\title{
Does B Cell Receptor Signaling in Chronic Lymphocytic Leukaemia Cells Differ from That in Other B Cell Types?
}

\author{
Joseph R. Slupsky \\ Department of Molecular and Clinical Cancer Medicine, University of Liverpool, 6th Floor, Duncan Building, Daulby Street, \\ Liverpool L69 3GA, UK
}

Correspondence should be addressed to Joseph R. Slupsky; jslupsky@liverpool.ac.uk

Received 27 February 2014; Accepted 2 June 2014; Published 2 July 2014

Academic Editor: Charlotte Guldborg Nyvold

Copyright (C) 2014 Joseph R. Slupsky. This is an open access article distributed under the Creative Commons Attribution License, which permits unrestricted use, distribution, and reproduction in any medium, provided the original work is properly cited.

Chronic lymphocytic leukaemia (CLL) is an incurable malignancy of mature B cells. CLL is important clinically in Western countries because of its commonality and because of the significant morbidity and mortality associated with the progressive form of this incurable disease. The B cell receptor (BCR) expressed on the malignant cells in CLL contributes to disease pathogenesis by providing signals for survival and proliferation, and the signal transduction pathway initiated by engagement of this receptor is now the target of several therapeutic strategies. The purpose of this review is to outline current understanding of the BCR signal cascade in normal B cells and then question whether this understanding applies to CLL cells. In particular, this review studies the phenomenon of anergy in CLL cells, and whether certain adaptations allow the cells to overcome anergy and allow full BCR signaling to take place. Finally, this review analyzes how BCR signals can be therapeutically targeted for the treatment of CLL.

\section{Introduction}

Chronic lymphocytic leukaemia (CLL) is a common malignancy of mature B cells, accounting for 34\% of all haematological cancers within the UK [1]. It represents a clinically important burden because there is significant morbidity and mortality associated with this disease, and currently it is incurable. Typically a patient with progressive disease will undergo several rounds of treatment and relapse before succumbing to the suppression of immune function and haemopoiesis that result from expansion of the malignant cells in hemic tissues. At the present time existing treatments focus on the prevention of disease progression and relief of symptoms [2]. However, new treatments specifically targeting the signaling pathway initiated following B cell antigen receptor (BCR) engagement are showing promise [3-5] and may lead to successful treatment of this disease. This review will assess current understanding of the BCR signaling pathway as it applies to CLL cells and discuss the potential for new therapies based on this understanding.

It is widely accepted that signals generated by engagement of the BCR play an important role in the pathogenesis of
CLL [6]. For instance, it is known that the structures of BCR expressed on CLL cells from different patients can resemble each other to a high degree, indicating that antigens of a similar nature drive development of the disease [7, 8]. The structure of the antigen binding domain of BCR expressed on CLL cells is biased towards a select number of immunoglobulin heavy-chain (IGHV) gene segments that have been rearranged in a very restricted manner $[8,9]$. In particular, the heavy-chain complementarity-determining region $(\mathrm{HCDR} 3)$ is longer than average $[9,10]$, and this feature has recently been demonstrated to play a role in cell-autonomous antigen-independent BCR signaling in CLL cells [11]. Furthermore, usage of IGHV genes such as 3-21 and 1-69 is associated with poor disease prognosis, whereas usage of genes such as $4-34$ and $2-30$ is associated with indolent disease [12]. Further difference between patients with progressive versus indolent disease appears to reside in specificity of antigen binding by the BCR, and this is defined by the degree to which mutation of the genes coding for a IGHV gene has affected the germline sequence. Those CLL patients which have malignant cells bearing IGHV gene sequences with greater than $98 \%$ homology to the germline 


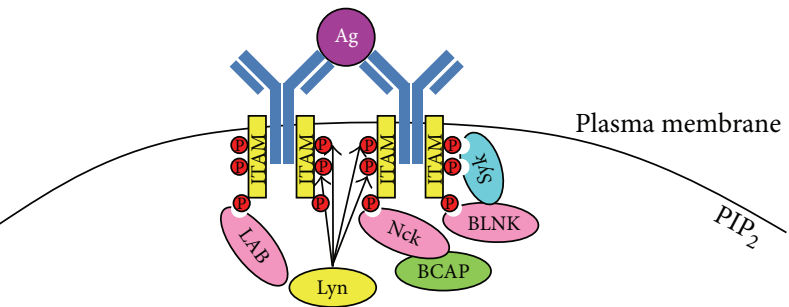

(a)

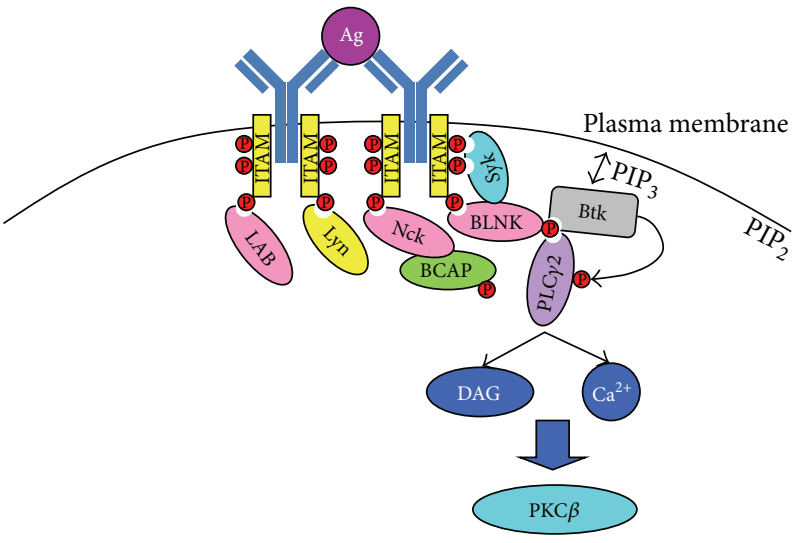

(c)

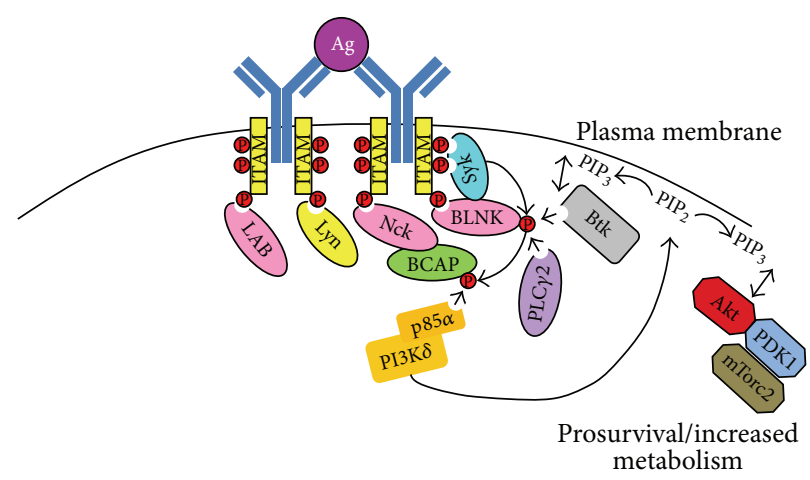

(b)

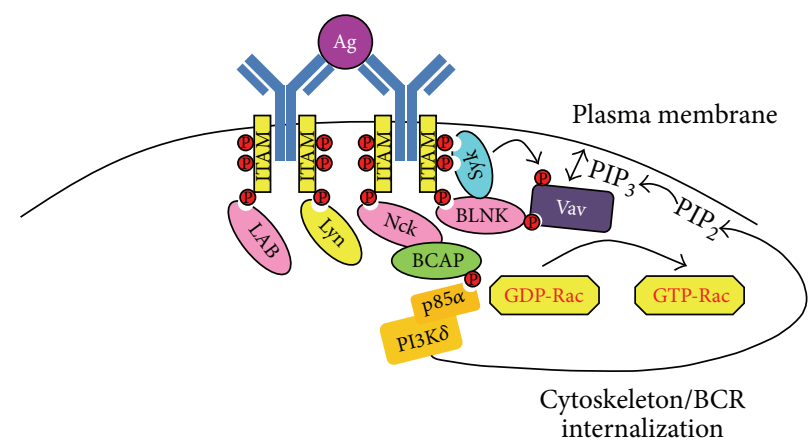

(d)

FIGURE 1: Induction of proximal BCR signaling. Illustration of the most proximal signals initiated during BCR engagement. (a) Antigen engagement of the BCR induces Lyn-mediated phosphorylation of CD79 on tyrosine residues within and outside the ITAM motif. This attracts adaptor molecules such as LAB, Nck, BCAP, and BLNK, as well as the tyrosine kinase Syk. (b) Syk binding to tyrosine phosphorylated CD79 induces its activation, and it phosphorylates BLNK, BCAP, and LAB. Phospho-BCAP attracts and activates PI3K $\delta$ and converts PIP 2 to $\mathrm{PIP}_{3}$. The presence of $\mathrm{PIP}_{3}$ on the plasma membrane attracts PDK1 and Akt; PDK1 phosphorylates and activates Akt, and this is followed by a second phosphorylation event by mTorc 2 . PIP ${ }_{3}$ on the plasma membrane also attracts Btk, which then binds to phospho-BLNK and exposes a phosphorylation site for Syk leading to autophosphorylation and full activation of Btk [17]. Phospho-BLNK also acts as a scaffold

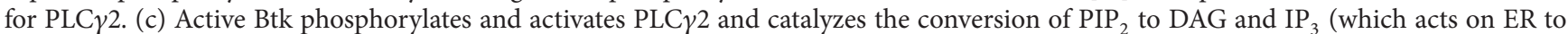
release intracellular $\mathrm{Ca}^{2+}$ ). DAG and $\mathrm{Ca}^{2+}$ then act to activate PKC $\beta$. (d) Phospho-BLNK and phospho-LAB serve as scaffolds for Vav, which

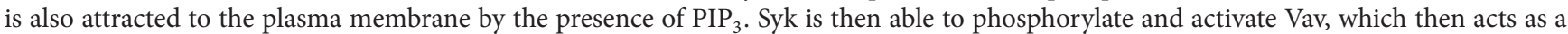
guanine exchange factor to convert GDP-Racl/2 to GTP-Rac1/2. This results in cytoskeletal changes and induction of BCR internalization.

sequence are termed unmutated CLL (UM-CLL), and those with less are termed mutated CLL (M-CLL). This is important because the BCR on M-CLL cells shows restricted antigen specificity compared to that on UM-CLL cells. Practically, this means that the BCR on different CLL cell clones may use the same IGHV genes, but the clone with unmutated genes will be polyreactive whereas the clone with mutated genes will be more monoreactive [13]. Thus, the polyreactivity of the BCR on UM-CLL cells allows binding to a variety of self and foreign antigens [14], and constitutive signals generated by this engagement are thought to contribute to disease progression. Proof of in vivo BCR engagement is suggested by Krysov et al. [15], who have shown that the BCR expressed on CLL cells, particularly from UM-CLL patients, has features that are associated with continuous in vivo exposure to antigen. Others have demonstrated that such in vivo BCR stimulation is reflected in the pattern of gene expression observed in freshly isolated cells [16]. Taken together, these observations suggest that targeting continuous BCR signaling may show therapeutic benefit in CLL patients with progressive disease, and this notion is now turned into a therapeutic strategy. New drugs that inhibit kinases within the BCR signaling pathway, notably ibrutinib (an inhibitor of Bruton's tyrosine kinase (Btk)), fostamatinib (an inhibitor of Syk), and idelalisib (an inhibitor of phosphatidylinositol 3 kinase $\delta(\mathrm{PI} 3 \mathrm{~K} \delta)$ ), all appear to show promise in clinical studies [3-5].

\section{BCR Signaling in Normal B Cells}

Our understanding of BCR signaling in CLL cells is based on a model that has been developed over many years. Figure 1 illustrates the signal transduction pathway that is activated by 


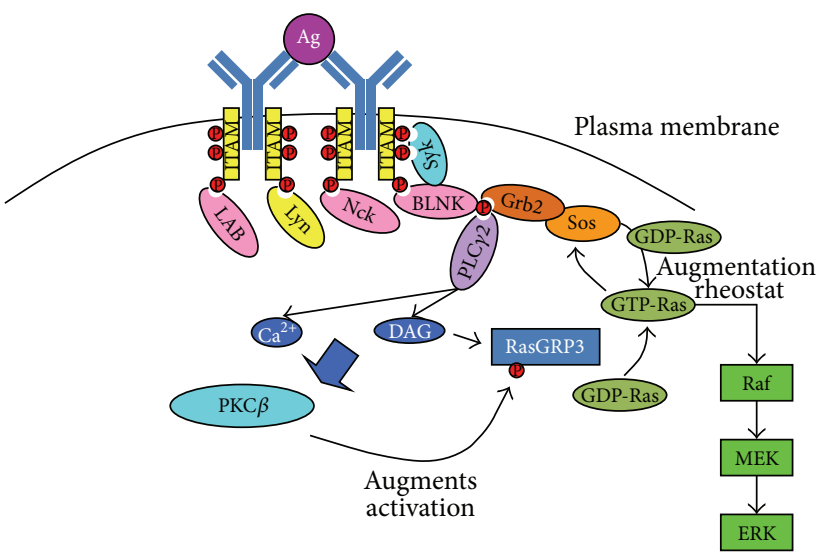

(a)

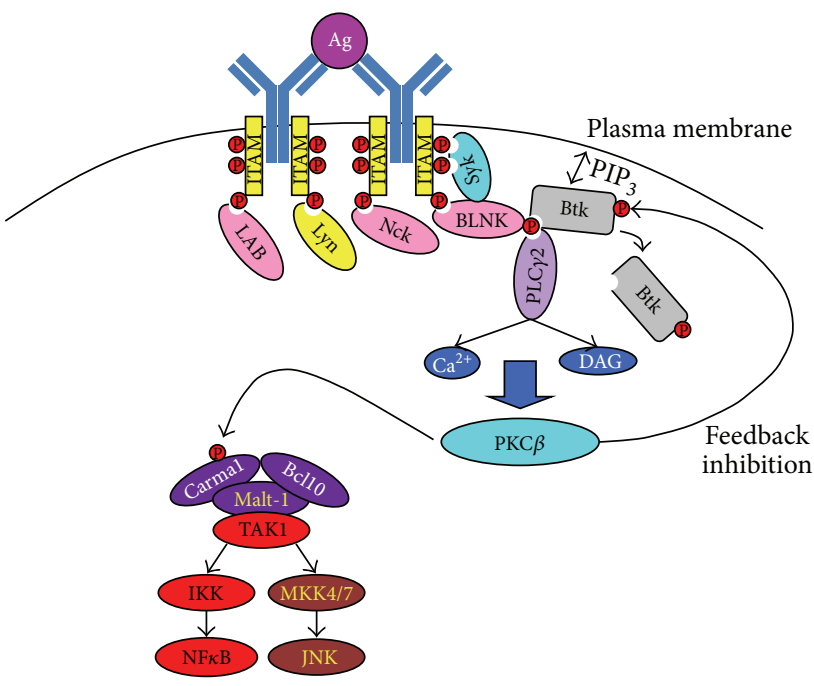

(b)

FIGURE 2: Signal integration following BCR engagement. Schematic of distal signaling events following BCR engagement. (a) Phospho-BLNK serves as a scaffold for Grb2, and this acts to prime activation of Sos. Active PKC $\beta$ phosphorylates RasGRP3 to facilitate its activation by DAG. The guanine exchange factor function of RasGRP3 converts GDP-Ras to GTP-Ras, which then acts to augment the guanine exchange factor function of Sos. Together RasGRP3 and Sos produce sufficient GTP-Ras to power activation of the MAPK cascade illustrated here by Raf, MEK, and ERK. (b) Active PKC $\beta$ acts to phosphorylate CARMA1 to induce assembly of the CARMA1-Bcl10-MALT1 complex. This allows activation of TAK1 which facilitates activation of the $\mathrm{NF} \kappa \mathrm{B}$ pathway by phosphorylating IKK and of the JNK pathway by phosphorylating MKK4 and MKK7. Active PKC $\beta$ also acts in a feedback inhibition loop by phosphorylating Btk on serine 180. This catalyzes the removal of Btk from the plasma membrane away from its substrate, PLC $\gamma 2$.

BCR stimulation [18]. Thus, upon BCR engagement the two tyrosine residues within the immune-receptor tyrosine-based activation motifs (ITAMs) of CD79a become phosphorylated by Src-family kinases (SFKs) $[19,20]$, specifically by Lyn, Fyn, and Blk, the three most abundant SFKs in B cells (Figure 1(a)) [21]. Phosphorylation of these two tyrosine residues in CD79 creates a binding site for the tandem SRChomology 2 (SH2) motifs within Syk [22], and this binding induces activation and phosphorylation of Syk [23]. Further propagation of the BCR signal is achieved by recruiting the adaptor proteins B cell linker (BLNK, SLP-65), linker of activation in B cells (LAB), and Nck to phosphotyrosine residues outside the ITAMs of CD79a and b [24-26]. Once bound to CD79, BLNK becomes a substrate for Syk [24], and this allows the recruitment of additional proteins such as Btk, phospholipase C $\gamma 2$ (PLC $\gamma 2$ ), Grb2, and Vav to the developing signalosome [27]. Nck recruits another adaptor protein, B cell adaptor for PI3K (BCAP), which becomes phosphorylated by Syk and acts to recruit and activate $\mathrm{PI} 3 \mathrm{~K} \delta$ by binding its associated $\mathrm{p} 85 \alpha$ regulatory subunit (Figure 1(b)) [28, 29]. Active $\mathrm{PI} 3 \mathrm{~K} \delta$ then provides phosphatidylinositol 3,4,5trisphosphate $\left(\mathrm{PIP}_{3}\right)$ to facilitate the recruitment of PDK1, Akt, Btk, PLC $\gamma 2$, and Vav to the plasma membrane via their pleckstrin homology $(\mathrm{PH})$ domains. The close juxtaposition of PDK1 with Akt stimulates threonine 308 phosphorylation and activation of Akt kinase function that is then stabilized by phosphorylation of serine 473 by mTorc2 [30]. The close juxtaposition of Syk, Btk, and PLC $\gamma 2$ at the B cell plasma membrane allows Syk and Btk to phosphorylate PLC $\gamma 2$ and induce its enzymatic activation (Figure 1(c)) [31].
What follows from this proximal signaling is an integration step that connects the BCR to gene transcription in the nucleus (Figure 2). Active PLC $\gamma 2$ hydrolyzes phosphatidylinositol 4,5-bisphosphate $\left(\mathrm{PIP}_{2}\right)$ to diacylglycerol (DAG) and inositol trisphosphate $\left(\mathrm{IP}_{3}\right)$. $\mathrm{IP}_{3}$ acts to release $\mathrm{Ca}^{2+}$ from intracellular stores within the endoplasmic reticulum and together with DAG activates classical protein kinase $\mathrm{C}$ isoforms, including PKC $\beta$ [32]. As illustrated in Figure 2(a) active $\mathrm{PKC} \beta$ phosphorylates the Ras guanine exchange protein (RasGEF) RasGRP3 facilitating its activation by DAG to generate active Ras (GTP-Ras) [33, 34]. This mechanism of GTP-Ras production then combines with that of Son-ofsevenless (Sos) primed for activation by Grb2 interaction with BLNK to act as a rheostat and augment the production of active Ras by Sos [35], eventually leading to efficient activation of the $c$ Raf-MEK-ERK pathway to transmit mitogenic signals to the nucleus. Activated PKC $\beta$ is also important for JNK and $\mathrm{NF} \kappa \mathrm{B}$ pathway activation in $\mathrm{B}$ cells undergoing BCR engagement (Figure 2(b)) [36]. A key target of PKC $\beta$ within this mechanism is CARMA1 (CARD11) [37], and this protein together with MALT1 and Bcl10 form a complex, known as the CBM complex, that then attracts and activates transforming growth factor $\beta$-activated kinase 1 (TAK1) [38, 39]. TAK1 then catalyzes activation of the $\mathrm{NF} \kappa \mathrm{B}$ pathway by phosphorylating IKK $\beta$ which goes on to phosphorylate and dissociate $\mathrm{I} \kappa \mathrm{B} \alpha$ from RelA to allow its translocation to the nucleus. TAK1 also catalyzes activation of the JNK pathway by phosphorylating MKK6 [38-40]. Finally, active PKC $\beta$ can phosphorylate Btk on $S^{180}$, and this promotes removal of Btk from the plasma membrane by interfering with the ability of 
its $\mathrm{PH}$ domain to bind $\mathrm{PIP}_{3}$ (Figure 2(b)). In this way, active $\mathrm{PKC} \beta$ provides feedback inhibition of BCR signaling [41].

$\mathrm{BCR}$ engagement also results in cytoskeletal changes that facilitate formation of the immunological synapse and induce adhesion (Figure 1(d)) [42, 43]. The RacGEF function of Vav is stimulated by Syk-induced phosphorylation when it locates to the plasma membrane in conjunction with LAB, BLNK, and $\mathrm{PIP}_{3}[26,27,42]$. The generation of active, GTP-loaded, Racl and Rac2 by Vav is then responsible for inducing the cytoskeletal changes that accompany BCR engagement [43]. Rac2 is essential for the activation of integrin lymphocyte functional antigen 1 (LFA1) during BCR engagement, and this is important for cell adhesion [42]. Both Racl and Rac2 are required to catalyze efficient $\mathrm{F}$-actin reorganization required for BCR internalization [26]. Active Racl and Rac2 generated by BCR cross-linking may also play an important role in activating the p38 MAPK pathway through interaction with MEKK3 [44].

Protein tyrosine phosphatases (PTPs) play an important role in the BCR signaling pathway [45]. CD45 and CD148 play overlapping functions in BCR signaling and catalyze the activation of Lyn by removing phosphate from the C-terminal inhibitory tyrosine residue [46]. Such removal catalyzes a structural change in Lyn that results in autophosphorylation of the activating tyrosine residue, and this stabilizes the SFK into its active state [47]. Thus, signaling is initiated when CD45/CD148 is excluded from areas of BCR clustering (synapse formation) [48] through a process that is thought analogous to a model of kinetic segregation proposed to occur in T cells [49].

More distal to the BCR are PTPN22, SHP-1, PTPN2, and PTP-PEST, which are primarily involved in downregulation of BCR signaling. PTPN22 forms a complex with the Cterminal SFK kinase (Csk) [50], and together these proteins likely act to deactivate Lyn and Fyn where PTPN22 initially dephosphorylates the activating tyrosine residue of these SFKs and Csk then acts to phosphorylate the inhibitory tyrosine residues [51]. PTPN22 is also reported to associate and dephosphorylate E3-ubiquitin ligase c-Cbl to potentially regulate its function in controlling Syk and Lyn stability [5254]. SHP-1 can also dephosphorylate the activating tyrosine residue of SFKs, but it has additional substrates such as ITAMs, ZAP70, Syk, and the BCR adaptor proteins BLNK and LAB [55]. Principally, SHP-1 is activated by coming into contact with phosphorylated tyrosines within immunereceptor tyrosine-based inhibition motifs (ITIMs) which are located on the cytoplasmic tails of cell surface proteins such as CD22 and CD32 [55]. Less is known about the functions of PTP-PEST and PTPN2 in B cells; PTP-PEST seems to downregulate BCR signaling by interacting with the adaptor protein Shc [56], whereas PTPN2 may have a role to play in regulating the activation of SFKs [57].

It is assumed that many of the signaling pathways initiated by BCR engagement in normal B cells are also initiated in CLL cells [6]. To a large extent this assumption can be substantiated; however, there are subtle differences that need to be taken into consideration. Importantly, BCR engagement elicits heterogeneous signaling responses with CLL cells from some cases having little or no response compared to cells from other cases $[58,59]$. This heterogeneity has been linked to disease prognosis [60], and, in general, UM-CLL cells have greater capacity to respond to BCR cross-linking than do MCLL cells $[59,61]$. Moreover, the ability to respond has been linked with B cell anergy, and CLL cells that do not respond to BCR engagement are thought to be anergic [59, 61-63]. Finally, CLL cells can express proteins typically found in $\mathrm{T}$ cells such as ZAP70 [64-66] and Lck [67-69], which can also contribute to heterogeneity of BCR signaling $[64,67,70,71]$.

\section{Anergy in CLL}

The stochastic nature of Ig gene rearrangement that takes place during $B$ cell development leads to the generation of self-reactive B cells, and it is estimated that the prevalence of these cells at the immature B cell stage lies between 55 and $70 \%$ of the total population [72]. Many of these selfreactive $\mathrm{B}$ cell clones are deleted either through a process of receptor editing that alters their specificity [73] or through the induction of apoptosis [74]. The rest escape the bone marrow and their reactivity is silenced by receptor anergy whereby self-reactive B cells become tolerant to autoantigens [75]. Importantly, many of these anergic B cells eventually die in circulation because they are denied BAFF, a TNF-related factor that potently promotes B cell survival $[76,77]$. If BAFF is provided, the state of anergy can be reversed, resulting in the development of autoimmunity $[78,79]$.

CLL can be considered a disease of autoreactive B cells because the malignant cells from approximately half of all CLL cases secrete antibodies against autoantigens [80, 81]. In fact, mutation of nonautoreactive CLL antibody sequences from M-CLL cases to germline configuration is demonstrated to confer polyreactivity and autoreactivity on the resultant antibody [82]. This fact introduces the concept of anergy to CLL cell pathobiology owing to the possibility of constitutive engagement of the BCR on CLL cells in vivo $[63,83,84]$. Such engagement is observed in some, but not all, cases of CLL $[15,59,61-63,83,84]$, with affected cells showing higher levels of intracellular calcium and activation of ERK, characteristics of anergic B cells in a mouse model [85]. Similar to normal B cells [86] the effects of BCR anergy on affected CLL cells can act globally to inhibit signaling by other receptors and are demonstrated in a recent report showing that anergic CLL cells fail to migrate toward CXCL12 because endosome recycling of Rapl is impaired [87]. Under normal conditions B cells that are anergic to soluble antigens have short in vivo life spans [88]. This potentially applies to our concept of anergy in CLL because the studies describing this phenomenon have all used malignant cells isolated from blood $[63,84]$. When malignant cells are separated from this environment anergy is reversed, suggesting that whilst in the blood anergic CLL cells are exposed to soluble antigen. Such chronic exposure is reported to confer a survival signal on CLL cells $[63,83,84]$ and potentially releases them from requiring $\mathrm{BAFF}$ for long-term survival while autoantigen remains present. This is an important difference to normal B cells and possibly explains the association of CLL anergy with the indolent course of disease $[63,84]$. 
How differences between anergic CLL and normal B cells may be manifested is potentially in the way transduction of inhibitory signals is favored by constitutive BCR engagement in these cells. Active Lyn is a driver of inhibitory signaling during BCR engagement as indicated by the development of an autoimmune phenotype in Lyn-deficient mice $[89,90]$. The mechanism of inhibitory signaling pathway activation during chronic BCR engagement is thought mediated by active Lyn binding to monophosphorylated ITAMs within CD79 leading to recruitment, phosphorylation, and activation of SHIP-1 and its adaptor Dok-1 [86, 91, 92]. Importantly, Syk is not activated in anergic B cells despite active Lyn $[93,94]$ and this is likely because of its absolute need for dual phosphorylation of the ITAM within CD79. With this established role of active Lyn in providing inhibitory signaling in anergic B cells, it is remarkable that overexpression of constitutively active Lyn also results in the development of autoimmunity, seemingly because chronic negative signals are overridden by enhanced positive signals that eventually lead to a breakdown in tolerance within this system [95]. This is important to our understanding of BCR signaling in CLL cells because Lyn is overexpressed and constitutively active in these cells $[67,96]$. Constitutive activation of Lyn in CLL cells may be the result of chronic BCR engagement, but another proposed explanation is low expression levels of the protein tyrosine phosphatase PTPRO due to epigenetic silencing [97, 98]. However constitutive activation of Lyn is maintained; higher expression levels of this SFK in CLL cells are linked with progressive disease [99]. This suggests that CLL cells and B cells expressing constitutively active Lyn are similar with respect to the dominance of positive over negative BCR signaling, a notion that is strongly supported by observations of constitutively active Syk, Btk, and PLC $\gamma 2$ in CLL cells [100-103]. Nevertheless, the presence of negative signals seems to be important for the pathogenesis of CLL. Two studies of CD5 phosphorylation in CLL cells, one showing that active Lyn mediates the recruitment of SHP-1 to tyrosine phosphorylated CD5 to contribute to apoptosis resistance in CLL cells [104] and a second showing that constitutive phosphorylation of CD5 promotes expression of genes involved in the malignant phenotype of CLL cells, suggest that such negative signaling may be mediated by CD 5 [105]. Another study showing that overexpressed PTPN22 positively regulates Akt activation in CLL cells by affecting the ability of Lyn to phosphorylate CD22 and recruit SHIP1 [106] further substantiates a role for negative signals in CLL cell survival. Finally, a recently published abstract has provided support for Lyn-mediated negative signaling in CLL pathogenesis and reported that disease development is inhibited in the Tcl-1 transgenic mouse model of CLL, a model that closely mimics UM-CLL in humans $[107,108]$, when Lyn is deleted [109].

The transduction of inhibitory signals by constitutive BCR engagement is not well studied in CLL cells, probably because its role in pathogenesis of the disease is only recently recognized. Active Lyn in CLL cells could regulate additional inhibitory signaling by phosphorylating ITIMs within CD32b, CD72, CD22, and Siglec-10, all of which would then attract SHP-1 and SHIP-1 to initiate this process. This notion is supported by unpublished data from this laboratory showing that CD32b is constitutively phosphorylated on $\mathrm{Y}^{292}$ within its ITIM in CLL cells and that this can be inhibited by treating the cells with the pan-SFK inhibitor dasatinib. CD72 is expressed on CLL cells [110], but its phosphorylation has not been previously studied. It is a ligand for CD5 and may function in a cis-mediated fashion to promote the constitutive phosphorylation of this latter protein that is observed in CLL cells [104, 105]. CD22 and Siglec-10 are both members of a family of proteins known as sialic acid-binding immunoglobulin-type lectins (or sialyl adhesins) and bind to glycan residues containing $\alpha 2,6$-linked sialic acid. Whereas Siglec-10 expression on CLL cells has not yet been described, CLL cells do express CD22 at variable levels between patients [111]. How expression levels of CD22 affect CLL function is not known, but phosphorylation of this protein by Lyn is described [106] and unpublished data from this laboratory supports this observation. In terms of Siglec-10, it is likely that CLL cells also express this protein because it is expressed on CD5+ B cells [112] from which CLL cells are reported to derive [113]. Both CD22 and Siglec-10 are involved in maintaining $\mathrm{B}$ cell tolerance and associate with the BCR to regulate $\mathrm{Ca}^{2+}$ release during its engagement [114]. It is therefore tempting to speculate that high levels of CD22 and Siglec-10 on CLL cells may have a role in maintaining tolerance within anergised cells.

\section{Can Anergy Be Overcome in CLL Cells?}

It is important when considering anergy in CLL that this state is mainly associated with M-CLL cells, whereas BCR responsiveness is associated with UM-CLL cells [59, 61, 83]. This consideration is important because the antigen binding region of BCR on UM-CLL cells is polyreactive, whereas the same region of BCR on M-CLL cells is monoreactive [82]. Thus, if anergy is defined as BCR tolerance resulting from constitutive engagement with antigen, it is logical to assume that the state of anergy would be more associated with UMCLL cells owing to the polyreactivity of their BCR. This is not the case, and one reason could be that anergy is maintained in M-CLL cells because BCR has higher affinity for antigen due to the process of affinity maturation $[6,62]$, whereas anergy is neither induced nor maintained in UM-CLL cells because their BCR has less affinity for antigen. Evidence that affinity maturation has taken place in M-CLL cells is provided in a study suggesting that these cells are derived from a population of CD5+CD27+ postgerminal center B cells [113]. Moreover, low levels of surface Ig expressed on M-CLL compared to UM-CLL cells are consistent with the notion that M-CLL cells are anergic because maintenance of anergy in normal B cells leads to downregulation of surface Ig expression. However, Syk, Btk, and PLC $\gamma 2$ are all reported to be constitutively active in CLL cells [100-103], a feature which argues against anergy because Syk is not active in anergic B cells [93, 94]. Furthermore, one study analyzing the glycosylation of surface IgM on CLL cells has demonstrated that expression of immature mannosylated IgM corresponds with engagement of the BCR on both CLL and normal B cells and goes on to 
suggest that this also corresponds to CLL cells experiencing in vivo BCR stimulation [15]. Importantly, this study also demonstrates that expression of immature mannosylated IgM correlates with UM-CLL cases. An acknowledged weakness of this study is that, for technical reasons, only CLL cases with high levels of sIgM could be analyzed so it is not clear whether CLL cases with low levels of surface IgM have similar glycosylation patterns. Nevertheless, high surface IgM expression on CLL cells is associated with increased ability to respond to BCR engagement [115]. This suggests that, despite constitutive engagement of BCR, anergy is lost in UM-CLL cells so that positive signals are generated that then contribute more robustly to malignant cell survival.

In this respect, expression of microRNAs (miRs) targeting proteins important for maintaining negative BCR signaling may be one adaptation [116]. miR-155 targets SHIP-1 [117] and high expression of miR-155 is associated with UM-CLL cases [118], possibly leading to diminished ability to initiate the negative BCR signaling associated with anergy [86, 91, 92]. Other epigenetic events such as gene hypo/hypermethylation could lead to promotion or suppression of particular genes involved in BCR signaling. For example, methylation of the PTPRO gene leads to reduced expression of the phosphatase coded by this gene, and this may have the consequence of promoting the generation of active Lyn in CLL cells [97, 98]. Another protein affected by gene methylation status in CLL cells is ZAP70 [119-121] whose expression is normally restricted to $\mathrm{T}$ cells.

ZAP70 expression in CLL cells was first identified in a genetic screen comparing M- and UM-CLL cells and then further characterized as a marker of poor disease prognosis $[66,122,123]$. In particular, high ZAP70 expression is observed in UM-CLL cells $[65,66,83]$ where it appears to enhance BCR signaling $[64,70,71,124,125]$ and relieve the effects of anergy on chemokine-induced migration [126, 127]. Importantly, ectopic expression of ZAP70 in M-CLL cells enhances BCR signaling strength in these cells through a mechanism that is independent of both its kinase function and c-Cbl binding capacity $[70,71]$. This suggests that ZAP70 may act as an adaptor protein and restore or enhance BCR signaling in anergic CLL cells (Figure 3). It may do this by associating with talin in order to facilitate the interaction between integrin and $\mathrm{F}$-actin and restore migration to chemokines such as CXCL12 [128] and possibly also to enhance BCR-mediated cell adhesion through a mechanism involving PLC 2 and Btk $[129,130]$.

Figure 3 also illustrates that ZAP70 can associate with the GTPase RhoH [131], which plays an important role in antigen receptor signaling in T cells by recruiting both ZAP70 and Lck to the immunological synapse [132]. Expression of $\mathrm{RhoH}$ is a pathogenetic feature of CLL cells because deletion of this protein within the Tcl-1 transgenic mouse model of CLL delays development of the disease by affecting both BCR signaling [132] and cell migration/adhesion [133]. An additional component of this complex is hematopoietic lineage cell-specific protein 1 (HS1) whose phosphorylation and function in T cells depend on ZAP70 and Lck (Figure 3) [134]. HS1 is highly expressed in CLL cells [135-137] where it contributes to the cytoskeletal remodeling required for

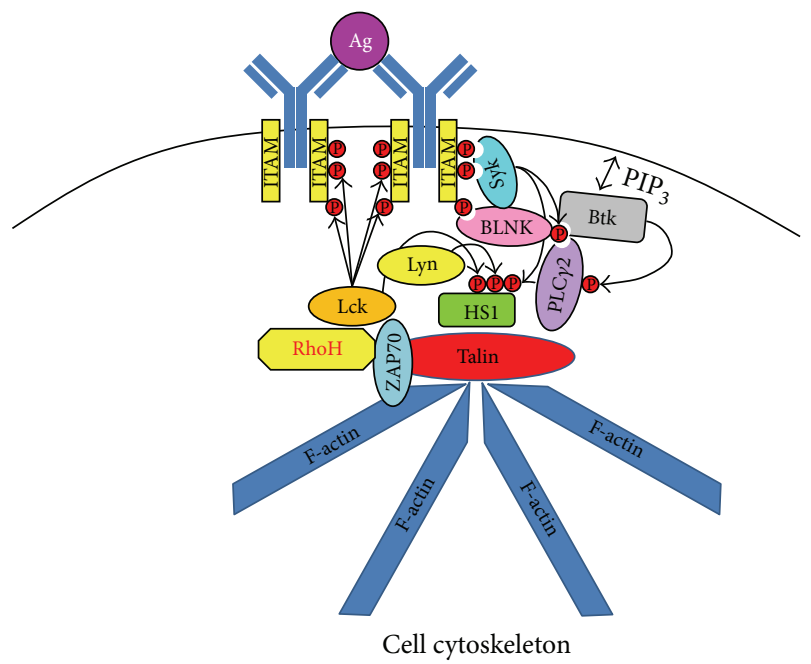

FIgUre 3: Possible roles of ZAP70, RhoH, and HS1 in BCR signaling in CLL cells. Schematic showing the potential role of ZAP70 as a scaffolding protein for Lck, RhoH, talin, and HS1 at the immunological synapse formed when the BCR is cross-linked on CLL cells. HS1 becomes hyperphosphorylated by Lyn, Syk, and Lck and plays a role with $\mathrm{RhoH}$ in regulating cytoskeletal remodeling.

cell movement and migration [138]. HS1 is a substrate of Syk and Lyn in B cells $[139,140]$ and of Lck in T cells $[134,141]$ that are undergoing antigen receptor stimulation, and phosphorylation of HS1 activates its function [134, 139, 141]. High levels of phospho-HS1 in CLL cells are correlated with poor disease prognosis [136], but it is suggested in this case that hyperphosphorylation of HS1 deactivates its function because deletion of this protein within the Tcl-1 mouse model of CLL accelerates disease progression [138]. Experiments using the pan-SFK inhibitor dasatinib suggest that Lyn is responsible for constitutive phosphorylation of HS1 in CLL cells [142], which makes sense because Lyn is constitutively active [96], but other SFKs such as Lck could be additionally involved because these cells both express Lck [68, 143, 144] and use it for mediating BCR signaling [67]. Thus, considering that RhoH expression correlates with ZAP70 in CLL cells, a plausible mechanism is that it coordinates ZAP70 and Lck to the BCR to facilitate hyperphosphorylation of HS1 during BCR engagement and thereby release CLL cells from the effects of anergy and promote increased cell mobility. Once CLL cells move into circulation they would then recover from antigen engagement and upregulate surface IgM and CXCR4 expression potentially enhancing their ability to reenter tissues and undergo proliferative/prosurvival signals that include BCR engagement as has been proposed $[115,145]$.

Other mechanisms facilitating the generation of positive BCR signals in CLL cells may also operate. At least one study has shown that CLL cells lacking ZAP70 can still signal via BCR engagement [83]. However UM-CLL cells overcome anergy to become able to signal through the BCR; there are still elements that remain unaccounted for. One such element is that BCR engagement on CLL cells does not induce activation of the JNK pathway regardless of whether 


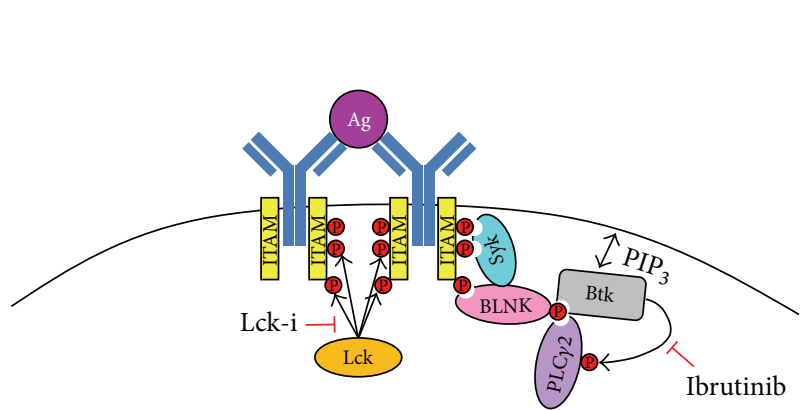

(a)

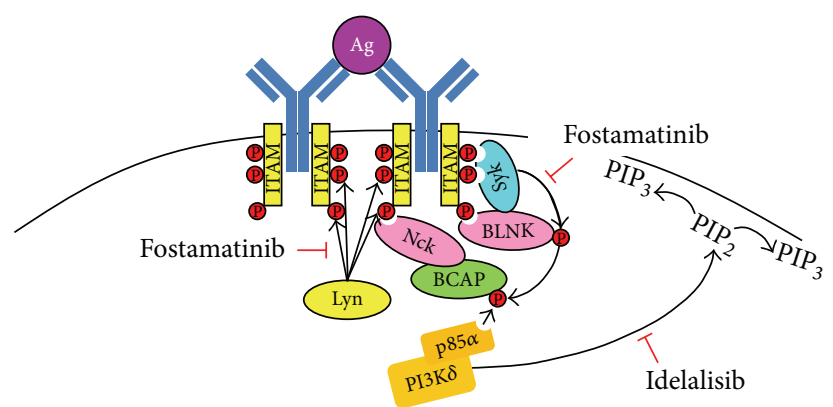

(b)

Figure 4: Points of inhibition for ibrutinib, idelalisib, fostamatinib, and Lck-i in the BCR signaling pathway. Illustration of proximal signals initiated during BCR engagement and points where well described inhibitors act. (a) Lck-i acts to inhibit the most proximal signaling event of SFK-mediated phosphorylation of tyrosine residues within CD79. Ibrutinib acts to inhibit the ability of Btk to phosphorylate and activate PLC $\gamma 2$ 2. (b) Fostamatinib acts to inhibit Syk kinase activity as well as that of Lyn. Idelalisib works to inhibit PI3K $\delta$ to limit the formation of $\mathrm{PIP}_{3}$ and has the effect of blocking membrane interaction of signaling proteins containing $\mathrm{PH}$ domains such as PDK1, Akt, and Btk.

the cells respond or not [146]. This is important to our understanding of anergy in CLL because the JNK pathway is not activated in BCR-stimulated normal anergic B cells [85]. As mentioned earlier, $\mathrm{PKC} \beta$ is a critical mediator of JNK pathway activation in $\mathrm{B}$ cells through its ability to interact with and activate CARMA1 during BCR engagement [39]. The gene for PKC $\beta$ codes for 2 splice variants, PKC $\beta$ I and PKC $\beta$ II [147], and work from this laboratory have shown that PKC $\beta$ II is overexpressed in CLL cells [148]. The isoform of PKC $\beta$ mediating CARMA1 phosphorylation in B cells has not been clearly identified [37], so it is conceivable that low expression of PKC $\beta$ I compared to PKC $\beta$ II in CLL cells [148] limits the ability of the former to phosphorylate CARMA1 and initiate JNK signaling.

It is also possible that anergy is masked in CLL by other factors. Thus, within the model of BCR signaling presented in Figure 1, when overexpressed PKC $\beta$ II is activated in CLL cells, the strength of induced BCR signals is reduced due to PKC-mediated phosphorylation of Btk and downregulation of the signal. VEGF stimulation of CLL cells stimulates PKC $\beta$ II activity, and this results in phosphorylation of Btk and inhibition of BCR signal strength [149]. Considering that CLL cells release autocrine VEGF and that high levels of this growth factor are present in lymph and splenic tissue where CLL cells proliferate $[150,151]$, it is entirely possible that BCR signaling is diminished when CLL cells are in tissues. When CLL cells emerge from tissues the effects of VEGF stimulation would wear off and result in apparent relief of BCR anergy.

\section{Targeting BCR Signaling in the Therapy of CLL}

Observations that Syk and Btk are constitutively active in CLL cells [100-103] have prompted the development of new agents targeting the BCR signaling pathway, and inhibitors of Btk, Syk, and PI3K $\delta$ have seen application in the therapy of CLL $[4,152-154]$. Of particular interest is ibrutinib (Figure 4(a)), which is a new class of compound that irreversibly blocks the kinase activity of Btk by covalently modifying Cys481 [155].
The presence of ibrutinib in CLL cell cultures is reported to induce apoptosis [156] and to also inhibit the prosurvival effects of BCR cross-linking and coculture with supporting nurse-like cells [3]. This effect of ibrutinib seems attributable to its ability to inhibit Btk because siRNA knockdown of this protein in CLL cells promotes apoptosis [100]. When used in vivo ibrutinib exhibits a profound effect and promotes rapid resolution of lymphadenopathy coupled with lymphocytosis of CLL cells $[152,157]$, presumably by inhibiting the ability of BCR to activate integrin $\alpha 4 \beta 1$ and maintain the adhesion required for their residence within proliferation centers [3, 130]. One report has suggested that ibrutinib also blocks in vivo cell proliferation based on studies of CLL cells derived from patients in phase $1 / 2$ clinical trials [158], while studies employing the Tcl-1 mouse model of CLL have shown that the presence of ibrutinib delays disease development [3, 100]. How anergy applies within the context of therapeutic response to ibrutinib is not clear, but it is suggested that a phenomenon defined as prolonged lymphocytosis, where white cell counts have not returned to normal or $<50 \%$ of baseline within 12 months of treatment, is the result of ibrutinib treatment when CLL cells are anergic [157]. Nevertheless, the high clinical efficacy, coupled with relatively low toxicities [152, 159], has accelerated this compound through to regulatory approval for the treatment of mantle cell lymphoma.

Inhibition of Syk with fostamatinib (Figure 4(b)) has also shown some promise in in vitro studies [4, 102, 103, 160], and this has led to the development of second-generation compounds that are reported to show greater specificity [161]. A recent study of CLL cells derived from patients enrolled in a phase $1 / 2$ clinical trial of fostamatinib has shown that this compound effectively blocks Btk activity and other BCR signaling targets in order to inhibit cell proliferation in treated patients [154], and an early report suggests that it is an effective treatment for this disease [4]. Active Syk contributes to CLL cell survival by regulating Mcll expression, and this was demonstrated using fostamatinib and siRNA knockdown of Syk expression [103, 162]. Fostamatinib is a competitive inhibitor of ATP and therefore limits the kinase activity of 
Syk [163]. However, fostamatinib is not strictly specific for Syk and other tyrosine kinases such as Lyn and Lck are also inhibited [163]. In this regard, fostamatinib is similar to the pan-SFK inhibitor dasatinib which has also been shown to have some efficacy as a single agent in the treatment of CLL [164]. This similarity extends to suggestions on their clinical use in combination with other agents; both fostamatinib and dasatinib are reported to work better when used in combination with fludarabine because of the potential influence of microenvironment in providing antiapoptotic signals $[102,165]$. Importantly, inhibition of Syk blocks CLL cell migration and adhesion $[160,166]$, and this may explain why reduction in lymphadenopathy is observed when this agent has been used in clinical trials.

Upstream of Btk is PI3K $\delta$ (Figures 1(a), 1(b), and 4(b)), which is a class Ia PI3K isoform whose expression is restricted to lymphoid cells and which plays an important role in B cell development $[167,168]$. In terms of CLL PI3K $\delta$ is an attractive target because of the nonredundant role it plays in relation to $\mathrm{PI} 3 \mathrm{~K} \alpha$ and $\beta$ with respect to $\mathrm{BCR}$ signaling [168]. An inhibitor for PI3K $\delta$ has been developed (Cal$101 /$ GS-1101/idelalisib) and preclinical studies have shown this compound is cytotoxic and blocks BCR signaling in CLL cells $[5,169]$. Like ibrutinib, idelalisib induces lymph node shrinkage and transient lymphocytosis when given in vivo [5]. Moreover, idelalisib might be highly suited to the treatment of CLL because it is reported to affect MZ and B-1 B cell function and reduce autoantibody response [170]. In clinical trials idelalisib shows antitumor activity when given as a single agent [171] and in combination with rituximab has been shown to significantly improve overall survival among patients with relapsed CLL [172].

Lck may also be a good therapeutic target in CLL (Figure 4(a)). It plays a major role in proximal and distal BCR signaling events in CLL cells [67], and an available inhibitor, 4-amino-5-(4-phenoxyphenyl)-7H-pyrrolo[3,2d]pyrimidin-7-yl-cyclopentane (Lck-i), is described to be highly selective in its ability to inhibit this SFK [173-175]. Indeed, when used at concentrations that inhibit BCR signaling to ERK, Akt, and IKK in CLL cells, this compound has no effect on the kinase activity of Lyn [67]. Moreover, the presence of Lck-i in CLL cell cultures does not affect constitutive phosphorylation of $\mathrm{Tyr}^{292}$ and $\mathrm{Tyr}^{822}$ within the respective ITIMs of $\mathrm{CD} 32 \mathrm{~b}$ and $\mathrm{CD} 22$, nor does it affect BCR-induced tyrosine phosphorylation of CD5 [176]. This suggests that Lck operates as a differential between negative and positive BCR signaling events in CLL cells, and inhibition of its activity would therefore allow negative BCR signals to dominate. Because of its proximal role in BCR signaling in CLL cells, the effects of Lck inhibition should be similar to idelalisib and ibrutinib and reduce lymphadenopathy and promote lymphocytosis.

Finally, argument can be made for targeting $\mathrm{PKC} \beta$ in the treatment of CLL. Although experiments have shown that inhibition of this PKC isozyme is not overtly cytotoxic to CLL cells [148], the fact that it is potentially regulating Btk function may be important to their pathophysiology $[148,149]$. PKC $\beta$ phosphorylates Btk on $S^{180}$ and facilitates its removal from the plasma membrane in activated B cells [41].
Inhibition of PKC $\beta$ in CLL cells may allow for greater membrane localization of Btk and make it more susceptible to agents such as ibrutinib. Thus, as a combination therapy PKC $\beta$ inhibitors may find use in the treatment of CLL.

\section{Conclusions and Perspectives}

It is clear that signals generated by the BCR play an important role in malignant cell survival and disease progression in CLL. It is now demonstrated that agents targeting this pathway are effective in the treatment of this disease. However, we do not yet fully understand the mechanism of BCR signaling in CLL cells, and new approaches are needed in this quest. Phosphoproteomic analysis of proteins using stable isotope labelling in culture (SILAC) may be one approach whereby a more complete picture can be made [177]. Indeed, one review has proposed that such an approach may be highly useful in the search for biomarkers in leukaemia and lymphoma [178]. One distinct advantage of this approach is the ability to decipher how agents targeting the BCR signaling pathway work. Alternatively, this approach may also give insight into the model of anergy that applies to CLL pathophysiology. Thus, with new understanding of how BCR signaling works and how it might be targeted in CLL cells, new therapies can be developed for the effective treatment of this disease.

\section{Conflict of Interests}

The author declares that there is no conflict of interests regarding the publication of this paper.

\section{Acknowledgments}

The author would like to thank Professor David MacEwan and Dr. John Allen of the University of Liverpool and Dr. Alison Michie of the University of Glasgow for critical reading of this paper.

\section{References}

[1] L. Watson, P. Wyld, and D. Catovsky, "Disease burden of chronic lymphocytic leukaemia within the European Union," European Journal of Haematology, vol. 81, no. 4, pp. 253-258, 2008.

[2] G. Dighiero and T. Hamblin, "Chronic lymphocytic leukaemia," The Lancet, vol. 371, no. 9617, pp. 1017-1029, 2008.

[3] S. Ponader, S.-S. Chen, J. J. Buggy et al., "The Bruton tyrosine kinase inhibitor PCI-32765 thwarts chronic lymphocytic leukemia cell survival and tissue homing in vitro and in vivo," Blood, vol. 119, no. 5, pp. 1182-1189, 2012.

[4] J. W. Friedberg, J. Sharman, J. Sweetenham et al., "Inhibition of Syk with fostamatinib disodium has significant clinical activity in non-Hodgkin lymphoma and chronic lymphocytic leukemia," Blood, vol. 115, no. 13, pp. 2578-2585, 2010.

[5] J. Hoellenriegel, S. A. Meadows, M. Sivina et al., "The phosphoinositide 3/-kinase delta inhibitor, CAL-101, inhibits Bcell receptor signaling and chemokine networks in chronic lymphocytic leukemia," Blood, vol. 118, no. 13, pp. 3603-3612, 2011. 
[6] F. K. Stevenson, S. Krysov, A. J. Davies, A. J. Steele, and G. Packham, "B-cell receptor signaling in chronic lymphocytic leukemia," Blood, vol. 118, no. 16, pp. 4313-4320, 2011.

[7] B. T. Messmer, E. Albesiano, D. G. Efremov et al., "Multiple distinct sets of stereotyped antigen receptors indicate a role for antigen in promoting chronic lymphocytic leukemia," Journal of Experimental Medicine, vol. 200, no. 4, pp. 519-525, 2004.

[8] F. Ghiotto, F. Fais, A. Valetto et al., "Remarkably similar antigen receptors among a subset of patients with chronic lymphocytic leukemia," Journal of Clinical Investigation, vol. 113, no. 7, pp. 1008-1016, 2004.

[9] F. Fais, F. Ghiotto, S. Hashimoto et al., "Chronic lymphocytic leukemia B cells express restricted sets of mutated and unmutated antigen receptors," The Journal of Clinical Investigation, vol. 102, no. 8, pp. 1515-1525, 1998.

[10] T. A. Johnson, L. Z. Rassenti, and T. J. Kipps, "Ig VH1 genes expressed in B cell chronic lymphocytic leukemia exhibit distinctive molecular features," Journal of Immunology, vol. 158, no. 1, pp. 235-246, 1997.

[11] M. D. von Minden, R. Übelhart, D. Schneider et al., "Chronic lymphocytic leukaemia is driven by antigen-independent cellautonomous signalling," Nature, vol. 489, no. 7415, pp. 309-312, 2012.

[12] K. Stamatopoulos, C. Belessi, C. Moreno et al., "Over 20\% of patients with chronic lymphocytic leukemia carry stereotyped receptors: pathogenetic implications and clinical correlations," Blood, vol. 109, no. 1, pp. 259-270, 2007.

[13] M. Hervé, K. Xu, Y. Ng et al., "Unmutated and mutated chronic lymphocytic leukemias derive from self-reactive B cell precursors despite expressing different antibody reactivity," The Journal of Clinical Investigation, vol. 115, no. 6, pp. 1636-1643, 2005.

[14] M. Hervé, K. Xu, Y. Ng et al., "Unmutated and mutated chronic lymphocytic leukemias derive from self-reactive B cell precursors despite expressing different antibody reactivity," Journal of Clinical Investigation, vol. 115, no. 6, pp. 1636-1643, 2005.

[15] S. Krysov, K. N. Potter, C. I. Mockridge et al., "Surface IgM of CLL cells displays unusual glycans indicative of engagement of antigen in vivo," Blood, vol. 115, no. 21, pp. 4198-4205, 2010.

[16] Y. Herishanu, P. Pérez-Galán, D. Liu et al., "The lymph node microenvironment promotes $\mathrm{B}$-cell receptor signaling, NF- $\kappa \mathrm{B}$ activation, and tumor proliferation in chronic lymphocytic leukemia," Blood, vol. 117, no. 2, pp. 563-574, 2011.

[17] Y. Baba, S. Hashimoto, M. Matsushita et al., "BLNK mediates Syk-dependent Btk activation," Proceedings of the National Academy of Sciences of the United States of America, vol. 98, no. 5, pp. 2582-2586, 2001.

[18] J. M. Dal Porto, S. B. Gauld, K. T. Merrell, D. Mills, A. E. PughBernard, and J. Cambier, "B cell antigen receptor signaling 101," Molecular Immunology, vol. 41, no. 6-7, pp. 599-613, 2004.

[19] X. R. Yao, H. Flaswinkel, M. Reth, and D. W. Scott, "Immunoreceptor tyrosine-based activation motif is required to signal pathways of receptor-mediated growth arrest and apoptosis in murine B lymphoma cells," Journal of Immunology, vol. 155, no. 2, pp. 652-661, 1995.

[20] M. Reth, "Antigen receptor tail clue," Nature, vol. 338, no. 6214, pp. 383-384, 1989.

[21] K. Saijo, C. Schmedt, I. Su et al., "Essential role of Src-family protein tyrosine kinases in NF- $\kappa \mathrm{B}$ activation during $\mathrm{B}$ cell development," Nature Immunology, vol. 4, no. 3, pp. 274-279, 2003.
[22] T. Kurosaki, S. A. Johnson, L. Pao, K. Sada, H. Yamamura, and J. C. Cambier, "Role of the Syk autophosphorylation site and $\mathrm{SH} 2$ domains in B cell antigen receptor signaling," Journal of Experimental Medicine, vol. 182, no. 6, pp. 1815-1823, 1995.

[23] R. B. Rowley, A. L. Burkhardt, H.-G. Chao, G. R. Matsueda, and J. B. Bolen, "Syk protein-tyrosine kinase is regulated by tyrosinephosphorylated $\operatorname{Ig} \alpha / \operatorname{Ig} \beta$ immunoreceptor tyrosine activation motif binding and autophosphorylation," Journal of Biological Chemistry, vol. 270, no. 19, pp. 11590-11594, 1995.

[24] S. Kabak, B. J. Skaggs, M. R. Gold et al., "The direct recruitment of BLNK to immunoglobulin $\alpha$ couples the B-cell antigen receptor to distal signaling pathways," Molecular and Cellular Biology, vol. 22, no. 8, pp. 2524-2535, 2002.

[25] A. Castello, M. Gaya, J. Tucholski et al., "Nck-mediated recruitment of BCAP to the BCR regulates the PI(3)K-Akt pathway in B cells," Nature Immunology, vol. 14, no. 9, pp. 966-975, 2013.

[26] S. Malhotra, S. Kovats, W. Zhang, and K. M. Coggeshall, "Vav and Rac activation in B cell antigen receptor endocytosis involves Vav recruitment to the adapter protein LAB," The Journal of Biological Chemistry, vol. 284, no. 52, pp. 3620236212, 2009.

[27] C. Fu, C. W. Turck, T. Kurosaki, and A. C. Chan, "BLNK: a central linker protein in B cell activation," Immunity, vol. 9, no. 1, pp. 93-103, 1998.

[28] T. Okada, A. Maeda, A. Iwamatsu, K. Gotoh, and T. Kurosaki, "BCAP: the tyrosine kinase substrate that connects B cell receptor to phosphoinositide 3-kinase activation," Immunity, vol. 13, no. 6, pp. 817-827, 2000.

[29] C.-M. Leu, "Nck, a missing adaptor between the B-cell receptor complex and the BCAP/PI3K/Akt pathway," Cellular \& Molecular Immunology, vol. 11, pp. 120-122, 2014.

[30] I. Hers, E. E. Vincent, and J. M. Tavaré, "Akt signalling in health and disease," Cellular Signalling, vol. 23, no. 10, pp. 1515-1527, 2011.

[31] Y. J. Kim, F. Sekiya, B. Poulin, S. G. Bae, and S. G. Rhee, "Mechanism of B-cell receptor-induced phosphorylation and activation of phospholipase C- $\gamma 2$," Molecular and Cellular Biology, vol. 24, no. 22, pp. 9986-9999, 2004.

[32] A. C. Newton, "Protein kinase C: poised to signal," American Journal of Physiology: Endocrinology and Metabolism, vol. 298, no. 3, pp. E395-E402, 2010.

[33] J. J. Coughlin, S. L. Stang, N. A. Dower, and J. C. Stone, "RasGRP1 and RasGRP3 regulate B cell proliferation by facilitating B cell receptor-Ras signaling," Journal of Immunology, vol. 175, no. 11, pp. 7179-7184, 2005.

[34] J. C. Stone, "Regulation and function of the RasGRP family of ras activators in blood cells," Genes and Cancer, vol. 2, no. 3, pp. 320-334, 2011.

[35] J. P. Roose, M. Mollenauer, M. Ho, T. Kurosaki, and A. Weiss, "Unusual interplay of two types of Ras activators, RasGRP and SOS, establishes sensitive and robust Ras activation in lymphocytes," Molecular and Cellular Biology, vol. 27, no. 7, pp. 2732-2745, 2007.

[36] H. Hara, T. Wada, C. Bakal et al., "The MAGUK family protein CARD11 is essential for lymphocyte activation," Immunity, vol. 18, no. 6, pp. 763-775, 2003.

[37] H. Shinohara, T. Yasuda, Y. Aiba et al., "PKC $\beta$ regulates BCRmediated IKK activation by facilitating the interaction between TAK1 and CARMA1," Journal of Experimental Medicine, vol. 202, no. 10, pp. 1423-1431, 2005. 
[38] H. Shinohara and T. Kurosaki, "Comprehending the complex connection between PKC $\beta$, TAK1, and IKK in BCR signaling," Immunological Reviews, vol. 232, no. 1, pp. 300-318, 2009.

[39] D. J. Rawlings, K. Sommer, and M. E. Moreno-García, "The CARMA1 signalosome links the signalling machinery of adaptive and innate immunity in lymphocytes," Nature Reviews Immunology, vol. 6, no. 11, pp. 799-812, 2006.

[40] C. Wang, L. Deng, M. Hong, G. R. Akkaraju, J. Inoue, and Z. J. Chen, "TAK1 is a ubiquitin-dependent kinase of MKK and IKK," Nature, vol. 412, no. 6844, pp. 346-351, 2001.

[41] S. W. Kang, M. I. Wahl, J. Chu et al., "PKC $\beta$ modulates antigen receptor signaling via regulation of Btk membrane localization," The EMBO Journal, vol. 20, no. 20, pp. 5692-5702, 2001.

[42] M. Weber, B. Treanor, D. Depoil et al., "Phospholipase C- $\gamma 2$ and Vav cooperate within signaling microclusters to propagate B cell spreading in response to membrane-bound antigen," Journal of Experimental Medicine, vol. 205, no. 4, pp. 853-868, 2008.

[43] E. Arana, A. Vehlow, N. E. Harwood et al., "Activation of the small GTPase Rac2 via the B cell receptor regulates B cell adhesion and immunological-synapse formation," Immunity, vol. 28, no. 1, pp. 88-99, 2008.

[44] X. Wang, F. Zhang, F. Chen et al., "MEKK3 regulates IFN- $\gamma$ production in $\mathrm{T}$ cells through the Racl/2-dependent MAPK cascades," Journal of Immunology, vol. 186, no. 10, pp. 5791-5800, 2011.

[45] I. Rhee and A. Veillette, "Protein tyrosine phosphatases in lymphocyte activation and autoimmunity," Nature Immunology, vol. 13, no. 5, pp. 439-447, 2012.

[46] J. W. Zhu, T. Brdicka, T. R. Katsumoto, J. Lin, and A. Weiss, "Structurally distinct phosphatases CD45 and CD148 both regulate $\mathrm{B}$ cell and macrophage immunoreceptor signaling," Immunity, vol. 28, no. 2, pp. 183-196, 2008.

[47] H. Yamaguchi and W. A. Hendrickson, "Structural basis for activation of human lymphocyte kinase Lck upon tyrosine phosphorylation," Nature, vol. 384, no. 6608, pp. 484-489, 1996.

[48] F. D. Batista, D. Iber, and M. S. Neuberger, "B cells acquire antigen from target cells after synapse formation," Nature, vol. 411, no. 6836, pp. 489-494, 2001.

[49] S. J. Davis and P. A. van der Merwe, "The kinetic-segregation model: TCR triggering and beyond," Nature Immunology, vol. 7, no. 8, pp. 803-809, 2006.

[50] J. Cloutier and A. Veillette, "Association of inhibitory tyrosine protein kinase p50(csk) with protein tyrosine phosphatase PEP in T cells and other hemopoietic cells," EMBO Journal, vol. 15, no. 18, pp. 4909-4918, 1996.

[51] J.-F. Cloutier and A. Veillette, "Cooperative inhibition of T-cell antigen receptor signaling by a complex between a kinase and a phosphatase," Journal of Experimental Medicine, vol. 189, no. 1, pp. 111-121, 1999.

[52] S. Cohen, H. Dadi, E. Shaoul, N. Sharfe, and C. M. Roifman, "Cloning and characterization of a lymphoid-specific, inducible human protein tyrosine phosphatase, Lyp," Blood, vol. 93, no. 6, pp. 2013-2024, 1999.

[53] H. W. Sohn, H. Gu, and S. K. Pierce, "Cbl-b negatively regulates B cell antigen receptor signaling in mature B cells through ubiquitination of the tyrosine kinase Syk," The Journal of Experimental Medicine, vol. 197, no. 11, pp. 1511-1524, 2003.

[54] Y. Shao, C. Yang, C. Elly, and Y.-C. Liu, "Differential regulation of the B cell receptor-mediated signaling by the $\mathrm{E} 3$ ubiquitin ligase Cbl," Journal of Biological Chemistry, vol. 279, no. 42, pp. 43646-43653, 2004.
[55] L. I. Pao, K. Badour, K. A. Siminovitch, and B. G. Neel, "Nonreceptor protein-tyrosine phosphatases in immune cell signaling," Annual Review of Immunology, vol. 25, no. 1, pp. 473523, 2007.

[56] D. Davidson and A. Veillette, "PTP-PEST, a scaffold protein tyrosine phosphatase, negatively regulates lymphocyte activation by targeting a unique set of substrates," The EMBO Journal, vol. 20, no. 13, pp. 3414-3426, 2001.

[57] F. Wiede, B. J. Shields, S. H. Chew et al., "T cell protein tyrosine phosphatase attenuates $\mathrm{T}$ cell signaling to maintain tolerance in mice," Journal of Clinical Investigation, vol. 121, no. 12, pp. 47584774, 2011.

[58] S. Nédellec, Y. Renaudineau, A. Bordron et al., "B cell response to surface IgM cross-linking identifies different prognostic groups of B-chronic lymphocytic leukemia patients," Journal of Immunology, vol. 174, no. 6, pp. 3749-3756, 2005.

[59] S. Lanham, T. Hamblin, D. Oscier, R. Ibbotson, F. Stevenson, and G. Packham, "Differential signaling via surface IgM is associated with $\mathrm{V}_{H}$ gene mutational status and CD38 expression in chronic lymphocytic leukemia," Blood, vol. 101, no. 3, pp. 1087-1093, 2003.

[60] P. Deglesne, N. Chevallier, R. Letestu et al., "Survival response to $\mathrm{B}$-cell receptor ligation is restricted to progressive chronic lymphocytic leukemia cells irrespective of Zap70 expression," Cancer Research, vol. 66, no. 14, pp. 7158-7166, 2006.

[61] D. J. Allsup, A. S. Kamiguti, K. Lin et al., "B-cell receptor translocation to lipid rafts and associated signaling differ between prognostically important subgroups of chronic lymphocytic leukemia," Cancer Research, vol. 65, no. 16, pp. 7328-7337, 2005.

[62] F. K. Stevenson and F. Caligaris-Cappio, "Chronic lymphocytic leukemia: revelations from the B-cell receptor," Blood, vol. 103, no. 12, pp. 4389-4395, 2004.

[63] M. Muzio, B. Apollonio, C. Scielzo et al., "Constitutive activation of distinct BCR-signaling pathways in a subset of CLL patients: a molecular signature of anergy," Blood, vol. 112, no. 1, pp. 188-195, 2008.

[64] L. Chen, G. Widhopf, L. Huynh et al., "Expression of ZAP-70 is associated with increased $\mathrm{B}$-cell receptor signaling in chronic lymphocytic leukemia," Blood, vol. 100, no. 13, pp. 4609-4614, 2002.

[65] M. Crespo, F. Bosch, N. Villamor et al., "ZAP-70 expression as a surrogate for immunoglobulin-variable-region mutations in chronic lymphocytic leukemia," The New England Journal of Medicine, vol. 348, no. 18, pp. 1764-1775, 2003.

[66] A. Wiestner, A. Rosenwald, T. S. Barry et al., "ZAP-70 expression identifies a chronic lymphocytic leukemia subtype with unmutated immunoglobulin genes, inferior clinical outcome, and distinct gene expression profile," Blood, vol. 101, no. 12, pp. 4944-4951, 2003.

[67] F. Talab, J. C. Allen, V. Thompson, K. Lin, and J. R. Slupsky, "LCK is an important mediator of B-cell receptor signaling in chronic lymphocytic leukemia cells," Molecular Cancer Research, vol. 11, no. 5, pp. 541-554, 2013.

[68] M. B. Majolini, M. M. D’Elios, P. Galieni et al., "Expression of the T-cell-specific tyrosine kinase Lck in normal B-1 cells and in chronic lymphocytic leukemia B cells," Blood, vol. 91, no. 9, pp. 3390-3396, 1998.

[69] J. C. Paterson, S. Tedoldi, A. Craxton et al., "The differential expression of LCK and BAFF-receptor and their role in apoptosis in human lymphomas," Haematologica, vol. 91, no. 6, pp. 772-780, 2006. 
[70] L. Chen, L. Huynh, J. Apgar et al., "ZAP-70 enhances IgM signaling independent of its kinase activity in chronic lymphocytic leukemia," Blood, vol. 111, no. 5, pp. 2685-2692, 2008.

[71] S. Gobessi, L. Laurenti, P. G. Longo, S. Sica, G. Leone, and D. G. Efremov, "ZAP-70 enhances B-cell-receptor signaling despite absent or inefficient tyrosine kinase activation in chronic lymphocytic leukemia and lymphoma B cells," Blood, vol. 109, no. 5, pp. 2032-2039, 2007.

[72] H. Wardemann, S. Yurasov, A. Schaefer, J. W. Young, E. Meffre, and M. C. Nussenzweig, "Predominant autoantibody production by early human B cell precursors," Science, vol. 301, no. 5638, pp. 1374-1377, 2003.

[73] D. Gay, T. Saunders, S. Camper, and M. Weigert, "Receptor editing: an approach by autoreactive B cells to escape tolerance," Journal of Experimental Medicine, vol. 177, no. 4, pp. 999-1008, 1993.

[74] D. A. Nemazee and K. Burki, "Clonal deletion of B lymphocytes in a transgenic mouse bearing anti-MHC class I antibody genes," Nature, vol. 337, no. 6207, pp. 562-566, 1989.

[75] G. J. V. Nossal and B. L. Pike, "Clonal anergy: persistence in tolerant mice of antigen-binding B lymphocytes incapable of responding to antigen or mitogen," Proceedings of the National Academy of Sciences of the United States of America, vol. 77, no. 3, pp. 1602-1606, 1980.

[76] M. Thien, T. G. Phan, S. Gardam et al., "Excess BAFF rescues self-reactive B cells from peripheral deletion and allows them to enter forbidden follicular and marginal zone niches," Immunity, vol. 20, no. 6, pp. 785-798, 2004.

[77] M. Batten, J. Groom, T. G. Cachero et al., "BAFF mediates survival of peripheral immature B lymphocytes," Journal of Experimental Medicine, vol. 192, no. 10, pp. 1453-1465, 2000.

[78] I. Mecklenbräuker, S. L. Kalled, M. Lettges, F. Mackay, and A. Tarakhovsky, "Regulation of B-cell survival by BAFF-dependent PKC $\delta$-mediated nuclear signalling," Nature, vol. 431, no. 7007, pp. 456-461, 2004.

[79] F. Mackay, S. A. Woodcock, P. Lawton et al., "Mice transgenic for BAFF develop lymphocytic disorders along with autoimmune manifestations," Journal of Experimental Medicine, vol. 190, no. 11, pp. 1697-1710, 1999.

[80] Z. M. Sthoeger, M. Wakai, D. B. Tse et al., "Production of autoantibodies by CD5-expressing B lymphocytes from patients with chronic lymphocytic leukemia," Journal of Experimental Medicine, vol. 169, no. 1, pp. 255-268, 1989.

[81] L. Borche, A. Lim, J. Binet, and G. Dighiero, "Evidence that chronic lymphocytic leukemia B lymphocytes are frequently committed to production of natural autoantibodies," Blood, vol. 76, no. 3, pp. 562-569, 1990.

[82] M. Hervé, K. Xu, Y.-S. Ng et al., "Unmutated and mutated chronic lymphocytic leukemias derive from self-reactive B cell precursors despite expressing different antibody reactivity," Journal of Clinical Investigation, vol. 115, no. 6, pp. 1636-1643, 2005.

[83] C. I. Mockridge, K. N. Potter, I. Wheatley, L. A. Neville, G. Packham, and F. K. Stevenson, "Reversible anergy of sIgMmediated signaling in the two subsets of CLL defined by VHgene mutational status," Blood, vol. 109, no. 10, pp. 4424-4431, 2007.

[84] B. Apollonio, C. Scielzo, M. T. S. Bertilaccio et al., "Targeting B-cell anergy in chronic lymphocytic leukemia," Blood, vol. 121, no. 19, pp. 3879-3888, 2013.

[85] J. I. Healy, R. E. Dolmetsch, L. A. Timmerman et al., "Different nuclear signals are activated by the $\mathrm{B}$ cell receptor during positive versus negative signaling," Immunity, vol. 6, no. 4, pp. 419-428, 1997.

[86] A. Brauweiler, K. Merrell, S. B. Gauld, and J. C. Cambier, "Cutting edge: acute and chronic exposure of immature B cells to antigen leads to impaired homing and SHIP1-dependent reduction in stromal cell-derived factor-1 responsiveness," Journal of Immunology, vol. 178, no. 6, pp. 3353-3357, 2007.

[87] D. S. Pye, I. Rubio, R. Pusch, K. Lin, A. R. Pettitt, and K. J. Till, "Chemokine unresponsiveness of chronic lymphocytic leukemia cells results from impaired endosomal recycling of rapl and is associated with a distinctive type of immunological anergy," The Journal of Immunology, vol. 191, no. 3, pp. 14961504, 2013.

[88] D. A. Fulcher and A. Basten, "Reduced life span of anergic self-reactive B cells in a double-transgenic model," Journal of Experimental Medicine, vol. 179, no. 1, pp. 125-134, 1994.

[89] V. W. F. Chan, F. Meng, P. Soriano, A. L. DeFranco, and C. A. Lowell, "Characterization of the B lymphocyte populations in lyn-deficient mice and the role of lyn in signal initiation and down-regulation," Immunity, vol. 7, no. 1, pp. 69-81, 1997.

[90] M. L. Hibbs, D. M. Tarlinton, J. Armes et al., "Multiple defects in the immune system of Lyn-deficient mice, culminating in autoimmune disease," Cell, vol. 83, no. 2, pp. 301-311, 1995.

[91] J. C. Cambier and A. Getahun, "B cell activation versus anergy; the antigen receptor as a molecular switch," Immunology Letters, vol. 128, no. 1, pp. 6-7, 2010.

[92] K. T. Merrell, R. J. Benschop, S. B. Gauld et al., "Identification of anergic B cells within a wild-type repertoire," Immunity, vol. 25, no. 6, pp. 953-962, 2006.

[93] G. A. Liubchenko, H. C. Appleberry, C. C. Striebich et al., "Rheumatoid arthritis is associated with signaling alterations in naturally occurring autoreactive B-lymphocytes," Journal of Autoimmunity, vol. 40, no. 1, pp. 111-121, 2013.

[94] B. J. Vilen, K. M. Burke, M. Sleater, and J. C. Cambier, “Transmodulation of BCR signaling by transduction-incompetent antigen receptors: Implications for impaired signaling in anergic B cells," Journal of Immunology, vol. 168, no. 9, pp. 43444351, 2002.

[95] M. L. Hibbs, K. W. Harder, J. Armes et al., "Sustained activation of Lyn tyrosine kinase in vivo leads to autoimmunity," Journal of Experimental Medicine, vol. 196, no. 12, pp. 1593-1604, 2002.

[96] A. Contri, A. M. Brunati, L. Trentin et al., "Chronic lymphocytic leukemia B cells contain anomalous Lyn tyrosine kinase, a putative contribution to defective apoptosis," Journal of Clinical Investigation, vol. 115, no. 2, pp. 369-378, 2005.

[97] T. Motiwala, S. Majumder, H. Kutay et al., "Methylation and silencing of protein tyrosine phosphatase receptor type $\mathrm{O}$ in chronic lymphocytic leukemia," Clinical Cancer Research, vol. 13, no. 11, pp. 3174-3181, 2007.

[98] T. Motiwala, J. Datta, H. Kutay, S. Roy, and S. T. Jacob, "Lyn kinase and ZAP70 are substrates of PTPROt in B-cells: Lyn inactivation by PTPROt sensitizes leukemia cells to VEGF-R inhibitor pazopanib," Journal of Cellular Biochemistry, vol. 110, no. 4, pp. 846-856, 2010.

[99] Y. Wang, L. Fan, L. Wang et al., "Expression levels of Lyn, Syk, PLC $\gamma 2$ and ERK in patients with chronic lymphocytic leukemia, and higher levels of Lyn are associated with a shorter treatmentfree survival," Leukemia and Lymphoma, vol. 54, no. 6, pp. 11651170, 2013.

[100] J. A. Woyach, E. Bojnik, A. S. Ruppert et al., "Bruton's tyrosine kinase (BTK) function is important to the development and 
expansion of chronic lymphocytic leukemia (CLL)," Blood, vol. 123, no. 8, pp. 1207-1213, 2014.

[101] Z. Song, P. Lu, R. R. Furman et al., "Activities of SYK and PLC $\gamma 2$ predict apoptotic response of CLL cells to SRC tyrosine kinase inhibitor dasatinib," Clinical Cancer Research, vol. 16, no. 2, pp. 587-599, 2010.

[102] M. Buchner, S. Fuchs, G. Prinz et al., "Spleen tyrosine kinase is overexpressed and represents a potential therapeutic target in chronic lymphocytic leukemia," Cancer Research, vol. 69, no. 13, pp. 5424-5432, 2009.

[103] S. Gobessi, L. Laurenti, P. G. Longo et al., "Inhibition of constitutive and BCR-induced Syk activation downregulates Mcl-1 and induces apoptosis in chronic lymphocytic leukemia B cells," Leukemia, vol. 23, no. 4, pp. 686-697, 2009.

[104] E. Tibaldi, A. M. Brunati, F. Zonta et al., "Lyn-mediated SHP-1 recruitment to CD5 contributes to resistance to apoptosis of Bcell chronic lymphocytic leukemia cells," Leukemia, vol. 25, no. 11, pp. 1768-1781, 2011.

[105] H. Gary-Gouy, A. Sainz-Perez, J. Marteau et al., "Natural phosphorylation of CD5 in chronic lymphocytic leukemia B cells and analysis of CD5-regulated genes in a B cell line suggest a role for CD5 in malignant phenotype," Journal of Immunology, vol. 179, no. 7, pp. 4335-4344, 2007.

[106] R. Negro, S. Gobessi, P. G. Longo et al., "Overexpression of the autoimmunity-associated phosphatase PTPN22 promotes survival of antigen-stimulated CLL cells by selectively activating AKT," Blood, vol. 119, no. 26, pp. 6278-6287, 2012.

[107] R. Bichi, S. A. Shinton, E. S. Martin et al., "Human chronic lymphocytic leukemia modeled in mouse by targeted TCL1 expression," Proceedings of the National Academy of Sciences of the United States of America, vol. 99, no. 10, pp. 6955-6960, 2002.

[108] X. Yan, E. Albesiano, N. Zanesi et al., "B cell receptors in TCL1 transgenic mice resemble those of aggressive, treatmentresistant human chronic lymphocytic leukemia," Proceedings of the National Academy of Sciences of the United States of America, vol. 103, no. 31, pp. 11713-11718, 2006.

[109] N. Reinart and M. Hallek, "Role of Lyn kinase in the pathogenesis of chronic lymphocytic leukemia," Blood, vol. 122, no. 21, p. 668, 2013.

[110] A. Cerutti, L. Trentin, R. Zambello et al., "The CD5/CD72 receptor system is coexpressed with several functionally relevant counterstructures on human B cells and delivers a critical signaling activity," Journal of Immunology, vol. 157, no. 5, pp. 1854-1862, 1996.

[111] J. Hulkkonen, L. Vilpo, M. Hurme, and J. Vilpo, "Surface antigen expression in chronic lymphocytic leukemia: clustering analysis, interrelationships and effects of chromosomal abnormalities," Leukemia, vol. 16, no. 2, pp. 178-185, 2002.

[112] A. Hoffmann, S. Kerr, J. Jellusova et al., "Siglec-G is a B1 cell-inhibitory receptor that controls expansion and calcium signaling of the B1 cell population," Nature Immunology, vol. 8, no. 7, pp. 695-704, 2007.

[113] M. Seifert, L. Sellmann, J. Bloehdorn et al., "Cellular origin and pathophysiology of chronic lymphocytic leukemia," The Journal of Experimental Medicine, vol. 209, no. 12, pp. 2183-2198, 2012.

[114] J. Jellusova and L. Nitschke, "Regulation of B cell functions by the sialic acid-binding receptors Siglec-G and CD22," Frontiers in Immunology, vol. 2, article 96, 2012.

[115] V. Coelho, S. Krysov, A. Steele et al., "Identification in CLL of circulating intraclonal subgroups with varying B-cell receptor expression and function," Blood, vol. 122, no. 15, pp. 2664-2672, 2013.
[116] M. Mraz and T. J. Kipps, "MicroRNAs and B cell receptor signaling in chronic lymphocytic leukemia," Leukemia and Lymphoma, vol. 54, no. 8, pp. 1836-1839, 2013.

[117] R. M. O'Connell, A. A. Chaudhuri, D. S. Rao, and D. Baltimore, "Inositol phosphatase SHIP1 is a primary target of miR-155," Proceedings of the National Academy of Sciences of the United States of America, vol. 106, no. 17, pp. 7113-7118, 2009.

[118] G. A. Calin, M. Ferracin, A. Cimmino et al., "A microRNA signature associated with prognosis and progression in chronic lymphocytic leukemia," The New England Journal of Medicine, vol. 353, no. 17, pp. 1793-1801, 2005.

[119] R. Claus, D. M. Lucas, S. Stilgenbauer et al., "Quantitative DNA methylation analysis identifies a single $\mathrm{CpG}$ dinucleotide important for ZAP-70 expression and predictive of prognosis in chronic lymphocytic leukemia," Journal of Clinical Oncology, vol. 30, no. 20, pp. 2483-2491, 2012.

[120] M. Corcoran, A. Parker, J. Orchard et al., "ZAP-70 methylation status is associated with ZAP-70 expression status in chronic lymphocytic leukemia," Haematologica, vol. 90, no. 8, pp. 1078$1088,2005$.

[121] S. Amin, M. Walsh, C. Wilson et al., "Cross-talk between DNA methylation and active histone modifications regulates aberrant expression of ZAP70 in CLL," Journal of Cellular and Molecular Medicine, vol. 16, no. 9, pp. 2074-2084, 2012.

[122] J. A. Orchard, R. E. Ibbotson, Z. Davis et al., "ZAP-70 expression and prognosis in chronic lymphocytic leukaemia," The Lancet, vol. 363, no. 9403, pp. 105-111, 2004.

[123] A. Rosenwald, A. A. Alizadeh, G. Widhopf et al., "Relation of gene expression phenotype to immunoglobulin mutation genotype in B cell chronic lymphocytic leukemia," Journal of Experimental Medicine, vol. 194, no. 11, pp. 1639-1647, 2001.

[124] L. Chen, J. Apgar, L. Huynh et al., "ZAP-70 directly enhances IgM signaling in chronic lymphocytic leukemia," Blood, vol. 105, no. 5, pp. 2036-2041, 2005.

[125] V. Pede, A. Rombout, J. Vermeire et al., "Expression of ZAP70 in chronic lymphocytic leukaemia activates NF- $\kappa$ B signalling," British Journal of Haematology, vol. 163, no. 5, pp. 621-630, 2013.

[126] S. J. Richardson, C. Matthews, M. A. Catherwood et al., "ZAP70 expression is associated with enhanced ability to respond to migratory and survival signals in B-cell chronic lymphocytic leukemia (B-CLL)," Blood, vol. 107, no. 9, pp. 3584-3592, 2006.

[127] E. Calpe, N. Purroy, C. Carpio et al., "ZAP-70 promotes the infiltration of malignant B-lymphocytes into the bone marrow by enhancing signaling and migration after CXCR4 stimulation," PLoS ONE, vol. 8, no. 12, Article ID e81221, 2013.

[128] Y. P. Lin, Y. J. Cheng, J. Y. Huang, H. C. Lin, and B. C. Yang, "Zap70 controls the interaction of talin with integrin to regulate the chemotactic directionality of T-cell migration," Molecular Immunology, vol. 47, no. 11-12, pp. 2022-2029, 2010.

[129] D. J. J. de Gorter, E. A. Beuling, R. Kersseboom et al., “Bruton's tyrosine kinase and phospholipase $\mathrm{C} \gamma 2$ mediate chemokinecontrolled B cell migration and homing," Immunity, vol. 26, no. 1, pp. 93-104, 2007.

[130] M. F. M. de Rooij, A. Kuil, C. R. Geest et al., "The clinically active BTK inhibitor PCI-32765 targets B-cell receptor- and chemokine-controlled adhesion and migration in chronic lymphocytic leukemia," Blood, vol. 119, no. 11, pp. 2590-2594, 2012.

[131] A. Sanchez-Aguilera, I. Rattmann, D. Z. Drew et al., "Involvement of RhoH GTPase in the development of B-cell chronic lymphocytic leukemia," Leukemia, vol. 24, no. 1, pp. 97-104, 2010. 
[132] Y. Gu, H.-D. Chae, J. E. Siefring, A. C. Jasti, D. A. Hildeman, and D. A. Williams, "RhoH GTPase recruits and activates Zap70 required for $\mathrm{T}$ cell receptor signaling and thymocyte development," Nature Immunology, vol. 7, no. 11, pp. 1182-1190, 2006.

[133] A. Troeger, A. J. Johnson, J. Wood et al., "RhoH is critical for cell-microenvironment interactions in chronic lymphocytic leukemia in mice and humans," Blood, vol. 119, no. 20, pp. 47084718, 2012.

[134] T. S. Gomez, S. D. McCarney, E. Carrizosa et al., "HS1 functions as an essential actin-regulatory adaptor protein at the immune synapse," Immunity, vol. 24, no. 6, pp. 741-752, 2006.

[135] A. Butrym, M. Majewski, J. Dzietczenia, K. Kuliczkowski, and G. Mazur, "High expression of hematopoietic cell specific Lyn substrate-1 (HS1) predicts poor survival of B-cell chronic lymphocytic leukemia patients," Leukemia Research, vol. 36, no. 7, pp. 876-880, 2012.

[136] C. Scielzo, P. Ghia, A. Conti et al., "HS1 protein is differentially expressed in chronic lymphocytic leukemia patient subsets with good or poor prognoses," Journal of Clinical Investigation, vol. 115, no. 6, pp. 1644-1650, 2005.

[137] F. Frezzato, C. Gattazzo, V. Martini et al., "HS1, a lyn kinase substrate, is abnormally expressed in B-chronic lymphocytic leukemia and correlates with response to fludarabine-based regimen," PLoS ONE, vol. 7, no. 6, Article ID e39902, 2012.

[138] C. Scielzo, M. T. S. Bertilaccio, G. Simonetti et al., "HS1 has a central role in the trafficking and homing of leukemic B cells," Blood, vol. 116, no. 18, pp. 3537-3546, 2010.

[139] Y. Yamanashi, T. Fukuda, H. Nishizumi et al., "Role of tyrosine phosphorylation of HS1 in B cell antigen receptor-mediated apoptosis," Journal of Experimental Medicine, vol. 185, no. 7, pp. 1387-1392, 1997.

[140] Y. Yamanashi, M. Okada, T. Semba et al., "Identification of HS1 protein as a major substrate of protein-tyrosine kinase(s) upon B-cell antigen receptor-mediated signaling," Proceedings of the National Academy of Sciences of the United States of America, vol. 90, no. 8, pp. 3631-3635, 1993.

[141] I. Taniuchi, D. Kitamura, Y. Maekawa, I. Fukuda, H. Kishi, and T. Watanabe, "Antigen-receptor induced clonal expansion and deletion of lymphocytes are impaired in mice lacking HS1 protein, a substrate of the antigen-receptor-coupled tyrosine kinases," EMBO Journal, vol. 14, no. 15, pp. 3664-3678, 1995.

[142] E. ten Hacken, C. Scielzo, M. T. S. Bertilaccio et al., “Targeting the LYN/HS1 signaling axis in chronic lymphocytic leukemia," Blood, vol. 121, no. 12, pp. 2264-2273, 2013.

[143] H. Abts, M. Jucker, V. Diehl, and H. Tesch, "Human chronic lymphocytic leukemia cells regularly express mRNAs of the protooncogenes lck and c-fgr," Leukemia Research, vol. 15, no. 11, pp. 987-997, 1991.

[144] M. W. Harr, P. F. Caimi, K. S. McColl et al., "Inhibition of Lck enhances glucocorticoid sensitivity and apoptosis in lymphoid cell lines and in chronic lymphocytic leukemia," Cell Death and Differentiation, vol. 17, no. 9, pp. 1381-1391, 2010.

[145] C. Calissano, R. N. Damle, S. Marsilio et al., "Intraclonal complexity in chronic lymphocytic leukemia: fractions enriched in recently born/divided and older/quiescent cells," Molecular Medicine, vol. 17, no. 11-12, pp. 1374-1382, 2011.

[146] A. Petlickovski, L. Laurenti, X. Li et al., "Sustained signaling through the B-cell receptor induces Mcl-1 and promotes survival of chronic lymphocytic leukemia B cells," Blood, vol. 105, no. 12 , pp. 4820-4827, 2005.
[147] G. C. Blobe, W. A. Khan, A. E. Halpern, L. M. Obeid, and Y. A. Hannun, "Selective regulation of expression of protein kinase C $\beta$ isoenzymes occurs via alternative splicing," Journal of Biological Chemistry, vol. 268, no. 14, pp. 10627-10635, 1993.

[148] S. T. Abrams, T. Lakum, K. Lin et al., "B-cell receptor signaling in chronic lymphocytic leukemia cells is regulated by overexpressed active protein kinase C $\beta$ II," Blood, vol. 109, no. 3, pp. 1193-1201, 2007.

[149] S. T. Abrams, B. R. B. Brown, M. Zuzel, and J. R. Slupsky, "Vascular endothelial growth factor stimulates protein kinase C $\beta$ II expression in chronic lymphocytic leukemia cells," Blood, vol. 115, no. 22, pp. 4447-4454, 2010.

[150] H. Chen, A. T. Treweeke, D. C. West et al., "In vitro and in vivo production of vascular endothelial growth factor by chronic lymphocytic leukemia cells," Blood, vol. 96, no. 9, pp. 3181-3187, 2000.

[151] M. Farahani, A. T. Treweeke, C. H. Toh et al., "Autocrine VEGF mediates the antiapoptotic effect of CD154 and CLL cells," Leukemia, vol. 19, no. 4, pp. 524-530, 2005.

[152] J. C. Byrd, R. R. Furman, S. E. Coutre et al., "Targeting BTK with ibrutinib in relapsed chronic lymphocytic leukemia," The New England Journal of Medicine, vol. 369, no. 1, pp. 32-42, 2013.

[153] S. E. M. Herman and A. J. Johnson, "Molecular pathways: targeting phosphoinositide 3-kinase p110-delta in chronic lymphocytic leukemia," Clinical Cancer Research, vol. 18, no. 15, pp. 4013-4018, 2012.

[154] S. E. M. Herman, P. M. Barr, E. M. McAuley, D. Liu, A. Wiestner, and J. W. Friedberg, "Fostamatinib inhibits B-cell receptor signaling, cellular activation and tumor proliferation in patients with relapsed and refractory chronic lymphocytic leukemia," Leukemia, vol. 27, no. 8, pp. 1769-1773, 2013.

[155] L. A. Honigberg, A. M. Smith, M. Sirisawad et al., "The Bruton tyrosine kinase inhibitor PCI-32765 blocks B-cell activation and is efficacious in models of autoimmune disease and B-cell malignancy," Proceedings of the National Academy of Sciences of the United States of America, vol. 107, no. 29, pp. 13075-13080, 2010.

[156] S. E. M. Herman, A. L. Gordon, E. Hertlein et al., "Bruton tyrosine kinase represents a promising therapeutic target for treatment of chronic lymphocytic leukemia and is effectively targeted by PCI-32765," Blood, vol. 117, no. 23, pp. 6287-6296, 2011.

[157] J. A. Woyach, K. Smucker, L. L. Smith et al., "Prolonged lymphocytosis during ibrutinib therapy is associated with distinct molecular characteristics and does not indicate a suboptimal response to therapy," Blood, vol. 123, no. 12, pp. 1810-1817, 2014.

[158] S. Cheng, J. Ma, A. Guo et al., "BTK inhibition targets in vivo CLL proliferation through its effects on B-cell receptor signaling activity," Leukemia, 2013.

[159] M. L. Wang, S. Rule, P. Martin et al., "Targeting BTK with ibrutinib in relapsed or refractory mantle-cell lymphoma," The New England Journal of Medicine, vol. 369, no. 6, pp. 507-516, 2013.

[160] M. P. Quiroga, K. Balakrishnan, A. V. Kurtova et al., "Bcell antigen receptor signaling enhances chronic lymphocytic leukemia cell migration and survival: specific targeting with a novel spleen tyrosine kinase inhibitor, R406," Blood, vol. 114, no. 5, pp. 1029-1037, 2009.

[161] J. Hoellenriegel, G. P. Coffey, U. Sinha et al., "Selective, novel spleen tyrosine kinase (Syk) inhibitors suppress chronic lymphocytic leukemia B-cell activation and migration," Leukemia, vol. 26, no. 7, pp. 1576-1583, 2012. 
[162] A. D. Baudot, P. Y. Jeandel, X. Mouska et al., "The tyrosine kinase Syk regulates the survival of chronic lymphocytic leukemia B cells through PKC and proteasome-dependent regulation of Mcl-1 expression," Oncogene, vol. 28, no. 37, pp. 3261-3273, 2009.

[163] H.-S. Cha, D. L. Boyle, T. Inoue et al., "A novel spleen tyrosine kinase inhibitor blocks c-Jun N-terminal kinase-mediated gene expression in synoviocytes," Journal of Pharmacology and Experimental Therapeutics, vol. 317, no. 2, pp. 571-578, 2006.

[164] P. C. Amrein, E. C. Attar, T. Takvorian et al., "Phase II study of dasatinib in relapsed or refractory chronic lymphocytic leukemia," Clinical Cancer Research, vol. 17, no. 9, pp. 2977-2986, 2011.

[165] A. M. Mccaig, E. Cosimo, M. T. Leach, and A. M. Michie, "Dasatinib inhibits B cell receptor signalling in chronic lymphocytic leukaemia but novel combination approaches are required to overcome additional pro-survival microenvironmental signals," British Journal of Haematology, vol. 153, no. 2, pp. 199-211, 2011.

[166] M. Buchner, C. Baer, G. Prinz et al., "Spleen tyrosine kinase inhibition prevents chemokine- and integrin-mediated stromal protective effects in chronic lymphocytic leukemia," Blood, vol. 115, no. 22, pp. 4497-4506, 2010.

[167] B. Vanhaesebroeck, M. J. Welham, K. Kotani et al., "p110 $\delta$, a novel phosphoinositide 3-kinase in leukocytes," Proceedings of the National Academy of Sciences of the United States of America, vol. 94, no. 9, pp. 4330-4335, 1997.

[168] S. T. Jou, N. Carpino, Y. Takahashi et al., "Essential, nonredundant role for the phosphoinositide 3-kinase p110 $\delta$ in signaling by the B-cell receptor complex," Molecular and Cellular Biology, vol. 22, no. 24, pp. 8580-8591, 2002.

[169] S. E. M. Herman, A. L. Gordon, A. J. Wagner et al., "Phosphatidylinositol 3-kinase- $\delta$ inhibitor CAL-101 shows promising preclinical activity in chronic lymphocytic leukemia by antagonizing intrinsic and extrinsic cellular survival signals," Blood, vol. 116, no. 12, pp. 2078-2088, 2010.

[170] C. A. Durand, K. Hartvigsen, L. Fogelstrand et al., "Phosphoinositide 3-kinase p $110 \delta$ regulates natural antibody production, marginal zone and B-1 B cell function, and autoantibody responses," The Journal of Immunology, vol. 183, no. 9, pp. 56735684, 2009.

[171] A. K. Gopal, B. S. Kahl, S. de Vos et al., "PI3K $\delta$ inhibition by idelalisib in patients with relapsed indolent lymphoma," The New England Journal of Medicine, vol. 370, no. 11, pp. 1008-1018, 2014.

[172] R. R. Furman, J. P. Sharman, S. E. Coutre et al., "Idelalisib and rituximab in relapsed chronic lymphocytic leukemia," The New England Journal of Medicine, vol. 370, no. 11, pp. 997-1007, 2014.

[173] L. D. Arnold, D. J. Calderwood, R. W. Dixon et al., "Pyrrolo[2,3d]pyrimidines containing an extended 5-substituent as potent and selective inhibitors of lck I," Bioorganic and Medicinal Chemistry Letters, vol. 10, no. 19, pp. 2167-2170, 2000.

[174] A. F. Burchat, D. J. Calderwood, G. C. Hirst et al., "Pyrrolo[2,3d]pyrimidines containing an extended 5-substituent as potent and selective inhibitors of lkc II," Bioorganic and Medicinal Chemistry Letters, vol. 10, no. 19, pp. 2171-2174, 2000.

[175] D. J. Calderwood, D. N. Johnston, R. Munschauer, and P. Rafferty, "Pyrrolo[2,3-d]pyrimidines containing diverse N-7 substituents as potent inhibitors of Lck," Bioorganic and Medicinal Chemistry Letters, vol. 12, no. 12, pp. 1683-1686, 2002.

[176] F. Talab, Identification of Lck as a key mediator of B cell receptor (BCR) signalling in chronic lymphocytic leukaemia [Ph.D. thesis], University of Liverpool, Liverpool, UK, 2013.
[177] G. Pimienta, R. Chaerkady, and A. Pandey, "SILAC for global phosphoproteomic analysis," in Phospho-Proteomics, M. Graauw, Ed., pp. 107-116, Humana Press, 2009.

[178] A. Zamò and D. Cecconi, "Proteomic analysis of lymphoid and haematopoietic neoplasms: there's more than biomarker discovery," Journal of Proteomics, vol. 73, no. 3, pp. 508-520, 2010. 


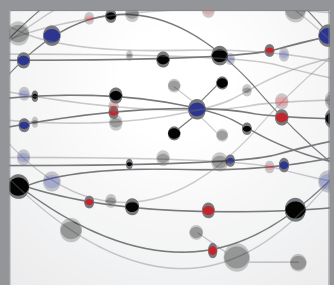

The Scientific World Journal
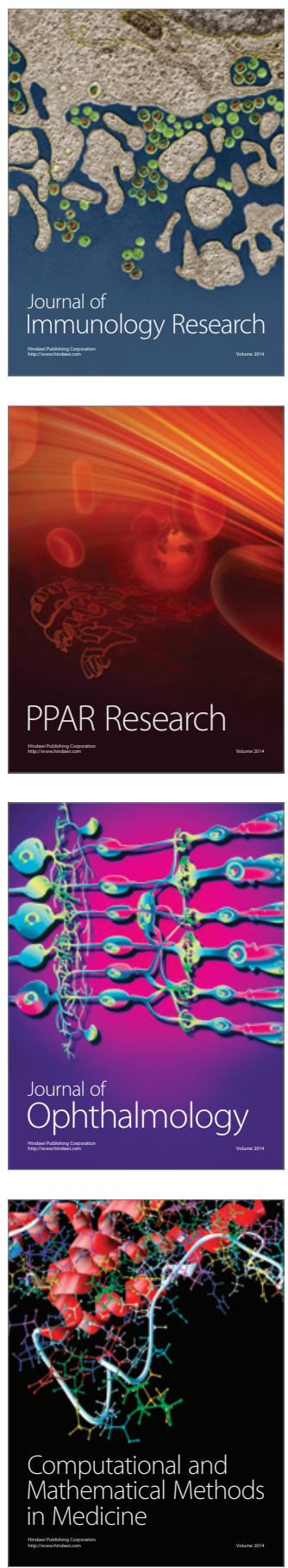

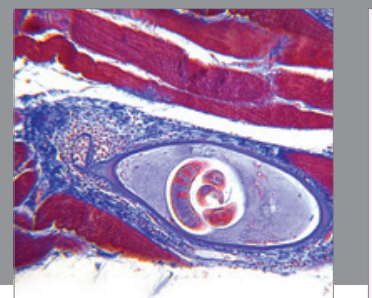

Gastroenterology

Research and Practice
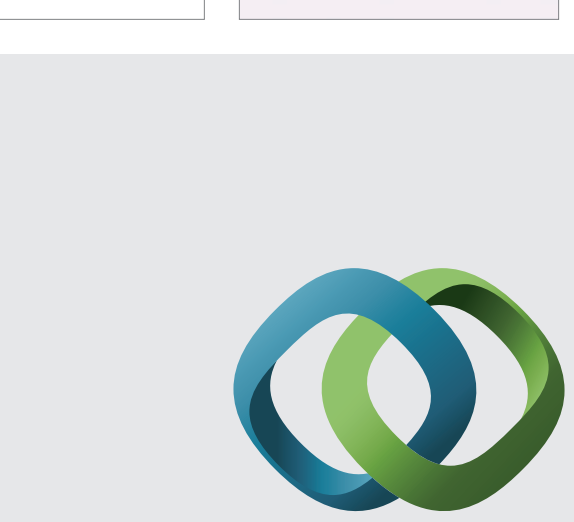

\section{Hindawi}

Submit your manuscripts at

http://www.hindawi.com
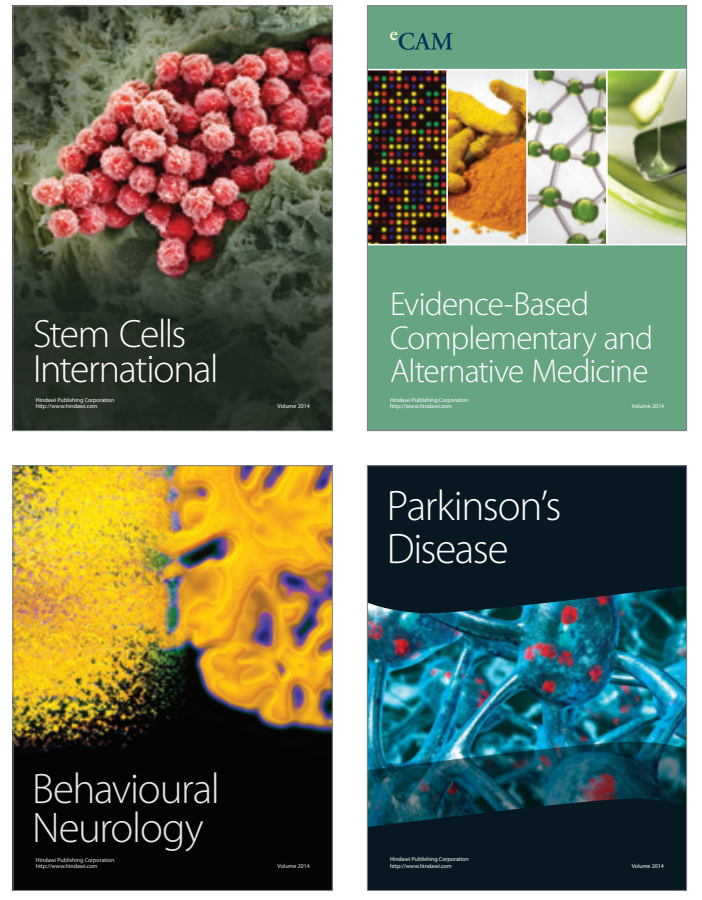
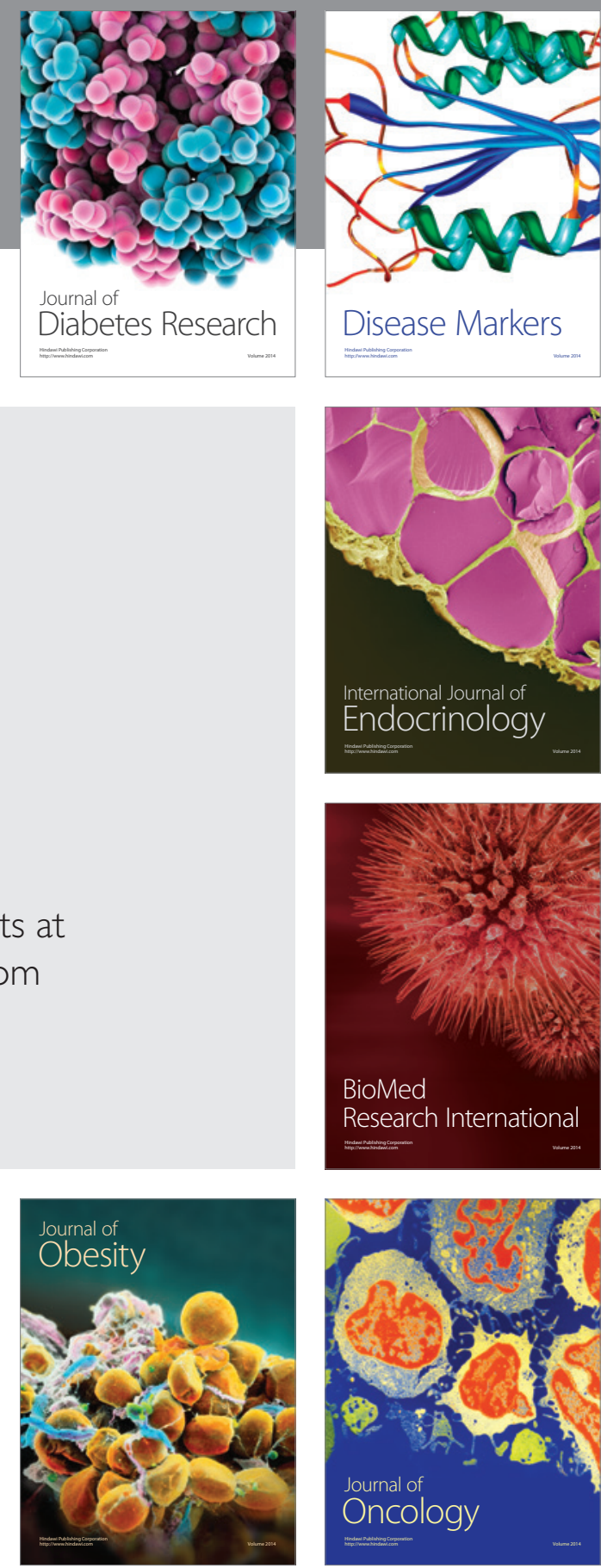

Disease Markers
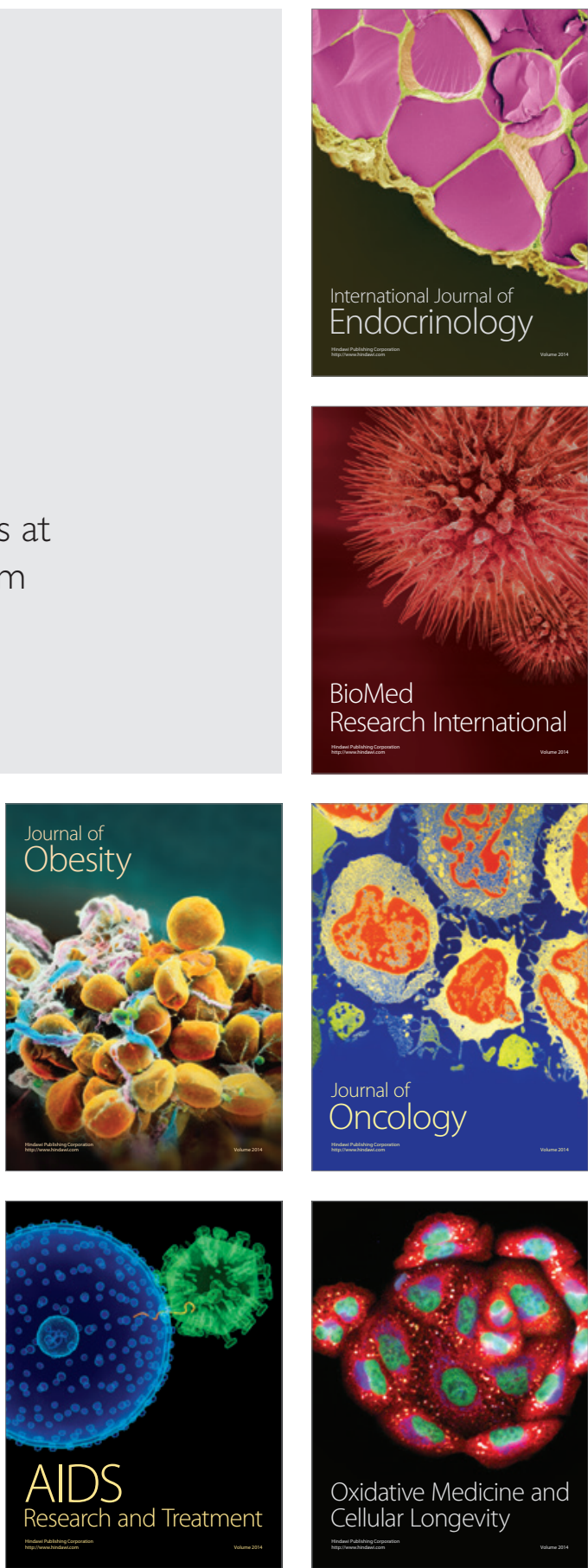